\title{
Mass Spectrometric Fragmentation of Isomeric 2-Alkyl-substituted 1,3-Indandiones and 3-Alkylidenephthalides: a Seven-step Consecutive Isomerization of Regular and Distonic Molecular Radical Cations ${ }^{\dagger}$
}

Dietmar Kuck

Fakultät für Chemie der Universität Bielefeld, Universitätsstrasse 25, D-33615 Bielefeld, Germany

\begin{abstract}
The electron impact-induced fragmentation of 2,2-dimethyl- and 2-ethyl-1,3-indandione, 1 and 2, and their isomers, 3-isopropylidene- and 3-propylidenephthalide, 3 and 4, respectively, was studied in detail by mass-analysed ion kinetic energy (MIKE) and collision-induced dissociation (CID-MIKE) spectrometry, including ${ }^{2} \mathrm{H}$ and ${ }^{13} \mathrm{C}$ labelled analogues of 1 and 2 . In all regimes of internal energy, the molecular ions $1^{+\cdot}-4^{+\cdot}$ interconvert by up to seven consecutive, reversible isomerization steps prior to the main fragmentation processes, viz. $\operatorname{loss}$ of $\mathrm{CH}_{3}{ }^{\circ}$ and $\mathrm{C}_{2} \mathrm{H}_{4} \cdot 1,3-$ Indandione and 3-methylenephthalide ions with identical alkylidene moieties (i.e. $1^{+\cdot} \rightleftharpoons 3^{+\cdot}$ and $2^{+\cdot} \rightleftharpoons$ $4^{+}$) equilibrate rapidly and completely prior to fragmentation, whereas these pairs of isomers interconvert only slowly via a five-step rearrangement of the indandione ions $1^{+\cdot} \rightleftharpoons 2^{+\cdot}$. Distinct from the behaviour of simpler ionized carbonyl species, a 1,2-C shift of a (formally) neutral carbonyl group is found to occur along with that of a protonated one. Also distinct from simpler cases, methyl loss does not take place from the ionized enol intermediates formed within the interconversion $1^{+\cdot} \rightleftharpoons 2^{+^{+}}$of the diketone ions but rather from the $n$-propylidenephthalide ions $4^{+\cdot}$. This follows from CID-MIKE spectrometry of the $\left|\mathrm{M}-\mathrm{CH}_{3}\right|^{+}$ions of 1-4 and two reference $\mathrm{C}_{10} \mathrm{H}_{7} \mathrm{O}_{2}^{+}(\mathrm{m} / z$ 159) ions of authentic structures (protonated 2-methylene-1,3-indandione and protonated 1,4naphthoquinone). The characteristic CID fragmentation of the $\mathrm{C}_{10} \mathrm{H}_{7} \mathrm{O}_{2}{ }^{+}$ions is rationalized. Finally, the multistep isomerization of ionized 1,3-indandiones apparently also extends to higher homologues $\mid$ e.g. $5^{+\cdot}$ from 2-ethyl-2-methyl-1,3-indandione (5) and $6^{+\cdot}$ from 2,2-diethyl-1,3-indandione (6)] : the ionized phthaloyl group of 1,3-indandione radical cations $1^{+\bullet}, 2^{+}, 5^{+\bullet}$ and $6^{+*}$, originally attached with its two acyl functionalities to the same carbon of the aliphatic chain, performs, in fact, a 'multi-step migration'.
\end{abstract}

\section{INTRODUCTION}

The interplay of unimolecular hydrogen abstraction and skeletal rearrangement processes during the mass spectrometric fragmentation of carbonyl compounds has been investigated in great detail during the past decade. ${ }^{1-4}$ One of the results emerging from these studies has been the fact that intramolecular abstraction of a $\beta-\mathrm{H}$ atom is similarly frequent and as important as the classical $\gamma-\mathrm{H}$ migration, ${ }^{5,6}$ which represents the first step of the McLafferty reaction (Scheme 1, $A \rightarrow B$ ). However, whereas the $\gamma-\mathrm{H}$ atom ends up in the fragment which does not contain the original donor site, the $\beta$-H atom is retained in the donor fragment (Scheme 1, $A \rightarrow C$ ). Therefore, the $\beta-\mathrm{H}$ migration has been referred to as 'hidden' hydrogen transfer. ${ }^{7}$ However, the fragmentation induced by this process is more complex than the McLafferty reaction. It consists of a series of skeletal and further hydrogen rearrangements obscuring the relationship between the structure of the precursor carbonyl compound and the fragmentation behaviour

$\uparrow$ Dedicated to Professor Dr Herbert Budzikiewicz on the occasion of his 60 th birthday.

CCC 0030-493X/94/030113-13

(C) 1994 by John Wiley \& Sons, Ltd. of its molecular ion. The mechanistic features of the two fragmentation processes are contrasted in Scheme 1.

This paper describes the mass spectrometric isomerization and fragmentation of two simple 2-alkyl-substituted 1,3-indandiones, 1 and 2, under electron impact (EI) ionization. 1,3-Indandiones have been widely studied in synthetic ${ }^{8}$ and physical organic ${ }^{9}$ chemistry and in pharmaceutical chemistry. ${ }^{10}$ In this laboratory, highly efficient synthetic routes to complex polycyclic organic structures have been developed in recent years using 1,3-indandiones as the starting materials. ${ }^{11}$ One of these investigations led us to a detailed analysis of the EI-induced fragmentation of 1,1,2,2,3,3-hexamethylindan, ${ }^{12}$ and in the course of that study we found that the radical cations of 1,3-indandiones show an interesting gas-phase ion chemistry on their own. These species undergo extended rearrangements in a multistep sequence, giving rise to apparently simple fragmentation reactions, viz. loss of methyl and ethene. It will be shown, however, that, in spite of the apparent complexity, the isomerization behaviour of 1,3-indandione radical cations may be mechanistically rationalized in full detail. Moreover, we found in the course of this study that isomeric 3-alkylidenephthalides $\mathbf{3}$ and $\mathbf{4}$, as 
(a)

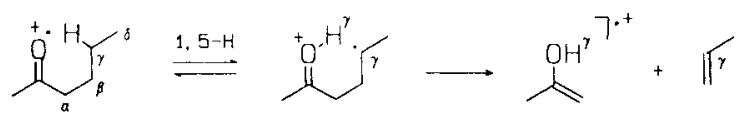

A

a

B

(b)
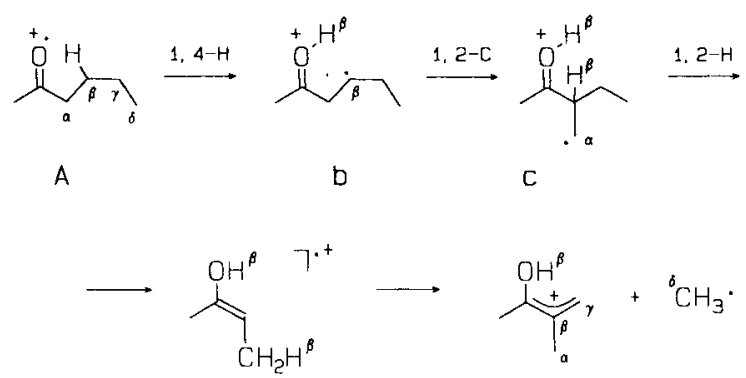

$\underbrace{\mathrm{OH}_{\gamma}^{\beta}}_{\gamma_{\alpha}}+{ }^{6} \mathrm{CH}_{3}$

d

C

Scheme 1

constitutional isomers of 1 and 2 , contribute considerably to the $\mathrm{C}_{11} \mathrm{H}_{10} \mathrm{O}_{2}^{+\cdot}$ isomerizing system.

With 1,3-diketones, the hidden hydrogen transfer sequence shown in Scheme 1 has not yet been observed. Rather, these species are prone to undergo the McLafferty reaction and/or eliminate carbon monoxide after intramolecular rearrangement processes involving distonic ions ${ }^{13}$ and ion-neutral complexes. ${ }^{14-18}$

\section{RESULTS AND DISCUSSION}

\section{Mass spectrometric 1,3-indandione $\rightleftharpoons 3$ - methylenephthalide rearrangement}

Compounds $1-4$ are closely related isomers which differ pairwise and complementarily in the topology of the aroyl moieties, on the one hand, and of the alkylidene moieties, on the other. Inspection of the standard $70 \mathrm{eV}$ El mass spectra (Fig. 1) and stable ion [collisioninduced dissociation-mass-analysed ion kinetic energy (CID-MIKE)] spectra (Fig. 2) reveals two sets of isomers with pairwise identical fragmentation. Thus, in both energy and lifetime regimes, the spectra of the isomers containing the 2-propylidene moiety ( 1 and 3 )<smiles>CC1(C)C(=O)c2ccccc2C1=O</smiles>

1<smiles>CC(C)=C1OC(=O)c2ccccc21</smiles>

3<smiles>CCC1C(=O)c2ccccc2C1=O</smiles>

2<smiles>CC/C=C1\OC(=O)c2ccccc21</smiles>

4 are indistinguishable, as are those of the isomers bearing the 1-propylidene group ( 2 and 4 ). Slight but significant differences are found, however, between the spectra of two isomers with different topology of the alkylidene moiety. Thus, the $70 \mathrm{eV}$ standard mass spectra of the two indandiones 1 and 2 and, consequently, those of the corresponding phthalides 3 and 4 differ in the ion abundance ratios $\left[\mathrm{M}-\mathrm{CH}_{3}\right]^{+} / \mathbf{M}^{+}$. and, more characteristically, in the ratio $[\mathrm{m} / \mathrm{z} 146] /[\mathrm{m} / \mathrm{z}$ 145]. Moreover, both the $70 \mathrm{eV}$ EI spectra and the CID spectra of the $n$-alkylidene isomers 2 and 4 display a characteristic peak at $\mathrm{m} / z 55\left(\mathrm{C}_{3} \mathrm{H}_{3} \mathrm{O}^{+}\right.$, see below). Likewise, the metastable ions (Table 1) of the four isomers are also pairwise identical.

High-resolution measurements of 1-4 revealed that the peak at $m / z 146$ consists of two components. In all cases, the major fraction $(\sim 90 \%)$ corresponds to the loss of ethene (e.g. 2, found $\mathrm{m} / \mathrm{z} 146.03678$, calculated 146.03623 for $\mathrm{C}_{9} \mathrm{H}_{6} \mathrm{O}_{2}^{+*}$ ), and the minor fraction $(\sim 10 \%)$ is due to loss of carbon monoxide (found $\mathrm{m} / \mathrm{z}$ 146.073 17, calculated 146.07262 for $\mathrm{C}_{10} \mathrm{H}_{10} \mathrm{O}^{+\bullet}$ ). Thus, in contrast to other 1,3-diketones, loss of $\mathrm{CO}$ from molecular ions of 2-alkyl-1,3-indandiones is only a minor process. This holds also for metastable ions (see below). Interestingly, high-resolution studies show that ions at $m / z 145$, being prominent only for the branched (isopropylidene) isomers 1 and 3 , are completely due to the loss of the elements of $\mathrm{CHO}^{\circ}$, and that ions at $\mathrm{m} / \mathrm{z}$ 131 are generated exclusively by elimination of the elements of $\mathrm{COCH}_{3}{ }^{\cdot}$ (presumably by consecutive losses of $\mathrm{CH}_{3}{ }^{\circ}$ and $\mathrm{CO}$, see below).

Table 1. Fragmentation of the metastable molecular ions of isomeric 1,3-indandiones and methylenephthalides 1-4 (MIKE spectra, $70 \mathrm{eV}$ )

\begin{tabular}{lccccc}
\multicolumn{1}{c}{ Loss of } & Ion & 1 & 2 & 3 & 4 \\
$\mathrm{CH}_{3}{ }^{-}$ & $m / z 159$ & 47.9 & 28.2 & 51.9 & 34.7 \\
$\mathrm{C}_{2} \mathrm{H}_{4}, \mathrm{CO}^{3}$ & $m / 2146$ & 52.1 & 72.8 & 48.1 & 65.3
\end{tabular}

a Loss of CO represents $\sim 5 \%$ of the total $[M-28]^{+*}$ ion current (cf. Table 2). 

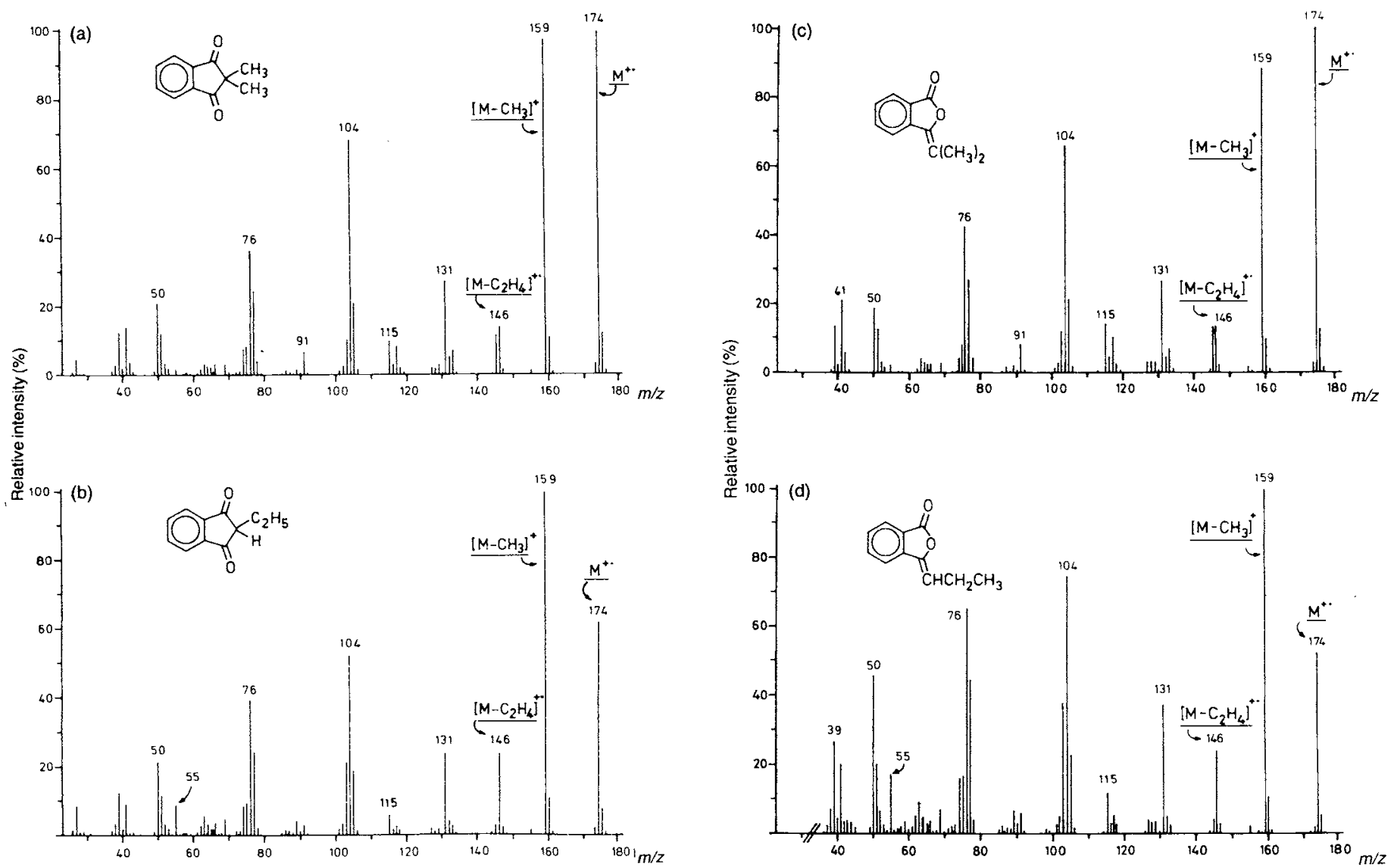

Figure 1. $70 \mathrm{eV} \mathrm{El} \mathrm{mass} \mathrm{spectra} \mathrm{of} \mathrm{(left)} \mathrm{isomeric} \mathrm{1,3-indandiones} 1$ and 2 and (right) 3-methylenephthalides 3 and 4, with (top) branched and (bottom) linear aliphatic $\mathrm{C}_{3}$ unit.

All these data demonstrate that the radical cations of 1,3-indandiones and 3-alkylidenephthalides with identical alkylidene groups undergo a fast and complete equilibration prior to fragmentation (Scheme 2). It is obvious that this isomerization takes place, in each set of isomeric molecular ions, by $\alpha$ cleavage at carbonyl functions followed by rotation and re-closure of the five-membered ring to give the corresponding isomer of similar stability $: 1^{+\cdot} \rightleftharpoons 3^{+\cdot}$ and $2^{+\cdot} \rightleftharpoons 4^{+\cdot}$. An analogous group tautomerization has been found earlier for the radical cations of substituted phthalimides. ${ }^{19}$ In solution, rearrangements of 3-alkylidenephthalides to the corresponding 2-alkyl-1,3-indandiones are catalysed by alkoxide ions and represent facile synthetic access to the latter compounds. ${ }^{20 a}$ Moreover, the photolytic conversion of 1,3-indandiones to methylenephthalides, e.g. of 1 and 5 (see below), was also described in a recent paper. $^{20 b}$

In contrast to the facile isomerization steps $1^{+\cdot} \rightleftharpoons 3^{+\cdot}$ and $2^{+\bullet} \rightleftharpoons 4^{+\cdot}$ being characterized by low critical ener-
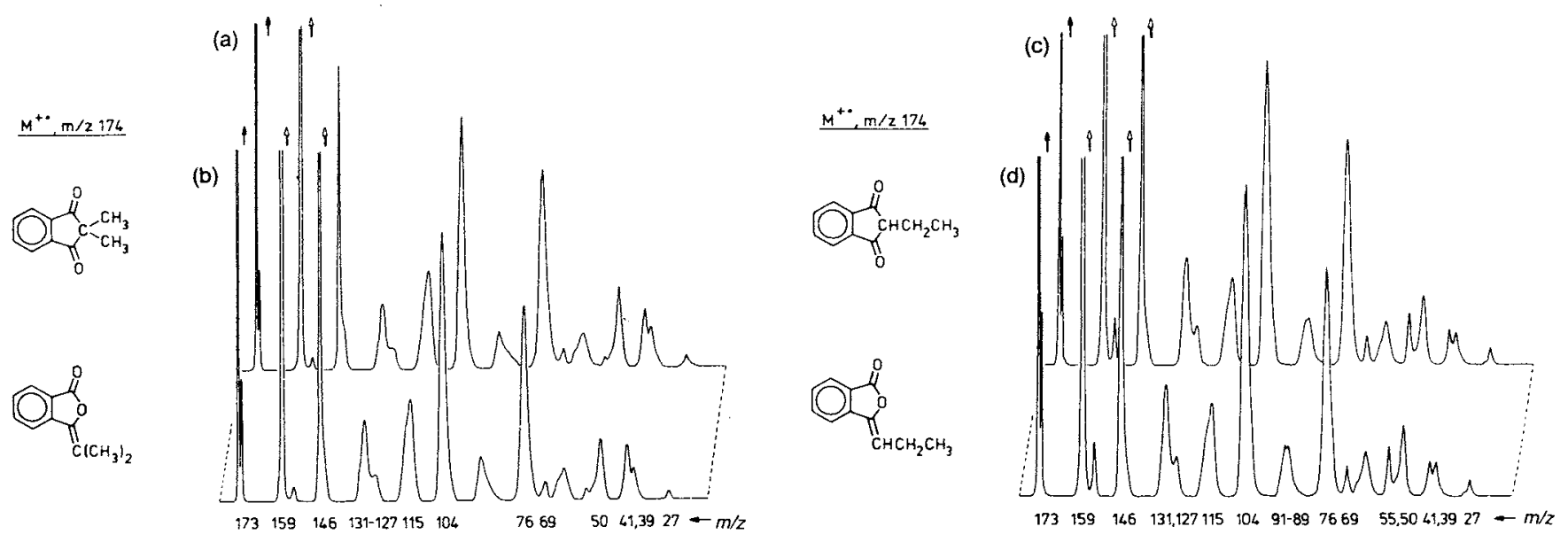

Figure 2. CID-MIKE spectra of the molecular ions of (left) 1 and 3 and (right) 2 and 4. 


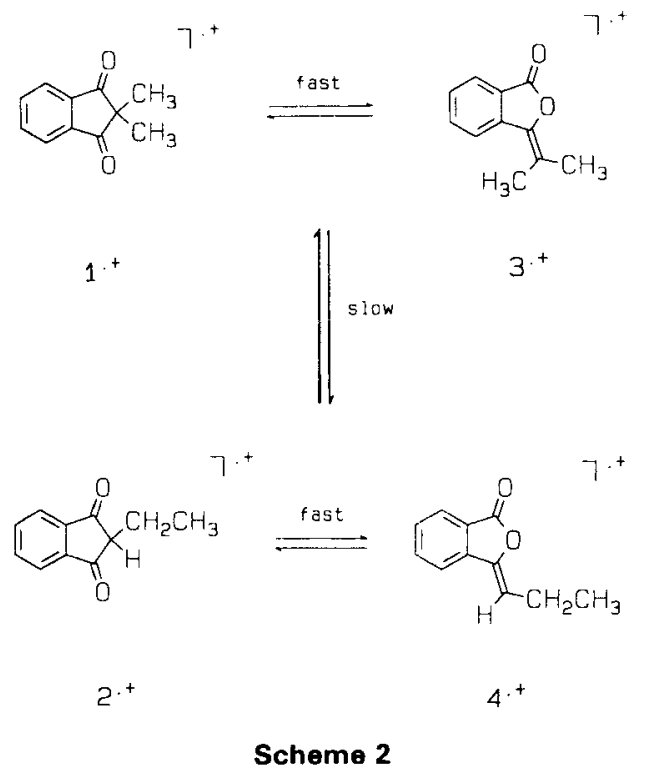

gies, the two sets of isomers interconvert less readily. Nevertheless, the primary fragmentation channels are the same for all of the four isomers, viz. elimination of comparable amounts of methyl and ethene along with minor fractions $(\sim 5 \%)$ of carbon monoxide. This follows both from the MIKE spectra and from highresolution measurements for metastable and unstable ions, respectively (Table 1). As will be shown below, this interconversion is effected by a slow but reversible, fivestep interconversion between the two indandione ions, $\mathbf{1}^{+\cdot} \rightleftharpoons 2^{+\cdot}$.

\section{Loss of $\mathrm{CH}_{3}{ }^{\cdot}$ and $\mathrm{C}_{2} \mathrm{H}_{4}$ from metastable indandione and phthalide ions}

From the mechanistic point of view, loss of methyl from ions $1^{+\cdot}-3^{+\cdot}$ and elimination of ethene for ions $1^{+\cdot}, 3^{+\cdot}$ and $4^{+\cdot}$ are not obvious. The only straightforward reaction path for ethene elimination is the McLafferty reaction of $2^{+*}$, giving rise to the enol ions of 1,3-indandione $(e, m / z 146$, Scheme 3$)$. In the case of the methyl loss, however, direct cleavage of the corresponding $\mathrm{C}-\mathrm{CH}_{3}$ bonds would give rise to extremely energetically unfavourable ('forbidden') structures, viz. ions $g$ and $h$ (Scheme 3), which certainly do not reside in minima of the energy hypersurface. ${ }^{21,22}$ Similarly, loss of methyl from $3^{+-}$and loss of ethene from $4^{+}$are energetically unreasonable. Facile methyl loss may occur exclusively from the phthalide ion $4^{+*}$, giving ion $f(m / z 159)$. Referring to the mechanism of alkyl loss from the simpler ionized carbonyl compounds, as shown in Scheme 1, loss of a methyl radical may be expected to occur also from enol-type isomers formed after appropriate hydrogen and carbon shifts. This would generate the isomeric $\left[\mathrm{M}-\mathrm{CH}_{3}\right]^{+}$ions $i$ and/or $j$, as indicated in Scheme 3 . It will be shown, however, that the isomerization behaviour of simpler molecular ions of carbonyl compounds makes only part of the overall isomerization sequence of indandione radical cations, and that the $[\mathrm{M}$ $\left.-\mathrm{CH}_{3}\right]^{+}$ions produced from $1^{+\cdot}-4^{+\cdot}$ are in fact ions $f$
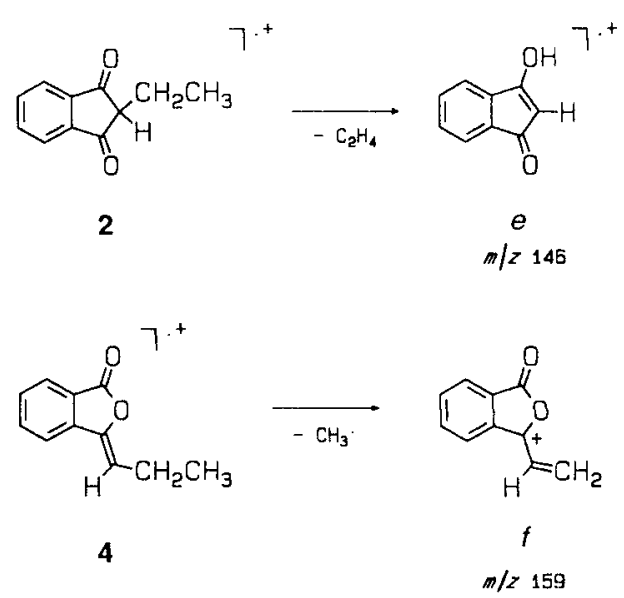

other $\left[\mathrm{M}-\mathrm{CH}_{3}\right]^{+}(\mathrm{m} / 2$ 159) ions:

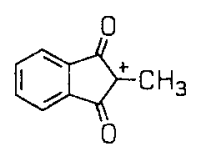

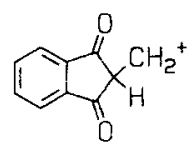

$h$

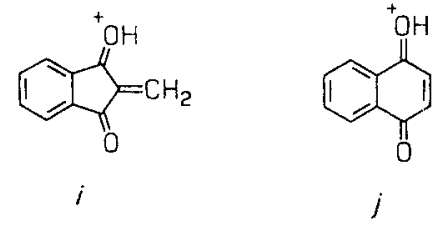

Scheme 3. Formation and structures of $\left[\mathrm{M}-\mathrm{C}_{2} \mathrm{H}_{4}\right]^{+\cdot}(m / z$ 146) and $\left[\mathrm{M}-\mathrm{CH}_{3}\right]^{+}(\mathrm{m} / z 159$ ions $)$.

generated exclusively by cleavage of the 1-propylidenephthalide ions $4^{+\bullet}$.

The MIKE spectra of the metastable molecular ions show that elimination of ethene gains importance with increasing ion lifetime. For the isomers bearing an isopropylidene group, $\mathbf{1}^{+\cdot}$ and $3^{+\cdot}$, the ratio $[\mathrm{M}$ $\left.-\mathrm{C}_{2} \mathrm{H}_{4}\right]^{+*} /\left[\mathrm{M}-\mathrm{CH}_{3}\right]^{+}$is close to unity (taking in account the minor contribution of $\mathrm{CO}$ loss), whereas for the $n$-propylidene isomers, loss of ethene dominates: [M $\left.-\mathrm{C}_{2} \mathrm{H}_{4}\right]^{+\cdot} /\left[\mathrm{M}-\mathrm{CH}_{3}\right]^{+} \approx 2$. This indicates that ethene loss is the slightly less energy-demanding fragmentation process, since no isomerization of the alkylidene moiety is required by starting from the $n$-propylidene isomers (see below).

\section{MIKE spectra of ${ }^{2} \mathrm{H}$ - and ${ }^{13} \mathrm{C}$-labelled indandiones}

Obviously, interconversion of the 2-propylidene isomers $1^{+\cdot}$ and $3^{+\cdot}$ into the 1 -propylidene congeners $2^{+\cdot}$ and $4^{+\cdot}$ requires profound skeletal reorganization. As already suggested in Scheme 2, this process is slow compared with the isomerization within the two sets of isomers. It proceeds by a five-step sequence starting from each of the two indandione ions. This picture develops from the analysis of the MIKE spectra of the molecular ions of several ${ }^{2} \mathrm{H}$ - and ${ }^{13} \mathrm{C}$-labelled isotopomers of the indandiones 1 and 2. The results are collected in Table 2. 
Table 2. Fragmentation of the metastable molecular ions of 2,2-dimethyl-1,3-indandiones 1-1c and 2-ethyl-1,3-indandiones 2 and 2 a (MIKE spectra, $\Sigma \%$ )

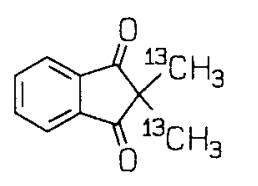

$1 \mathbf{a}$

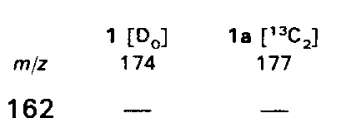

$161-0.0$

$160 \quad-\quad 49.0$

$159 \quad 47.9 \quad-$

152

151

150

149

148

147

146

a Loss of $\mathrm{C}_{2} \mathrm{H}_{4}$ (major) and of $\mathrm{CO}$ (minor, 5-10\%, component).

b Loss of $\mathrm{CO}$.

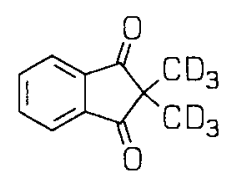

$1 b$

$1 \mathrm{~b}\left[\mathrm{D}_{6}\right]$
180

0.0

0.0

$\sim 0.6$

45.7

$4.7^{b}$

0.0

0.0

0.0

49.3

-

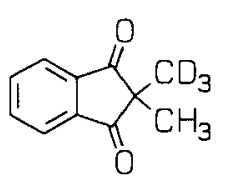

$1 c$

$1 \mathrm{c}\left[\mathrm{D}_{3}\right]$
176

20.2

0.0

$\sim 0.3$

34.2

$-$

-

0.0

40.6

0.0

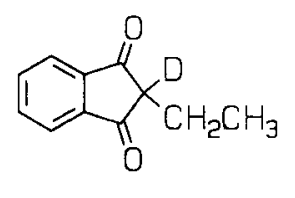

$2 a$

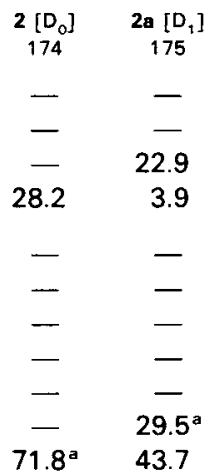

The mass shifts observed with the labelled ions indicate a highly specific isomerization process occurring without hydrogen or carbon interchange. Thus, the methyl radical expelled from ions $\mathbf{1 a}^{+\cdot}$ and $\mathbf{1 b}^{+\bullet}$ contains virtually all its original constituents (i.e. the ${ }^{13} \mathrm{C}^{\alpha}$ and $\mathrm{D}^{\alpha}$ atoms, respectively). The ethene molecules expelled from these isotopomers retain only one of the carbon atoms but all of the four hydrogen atoms available from the two methyl substituents. Hence, the central carbon atom [C-(2)] does not participate at all in the loss of methyl but does so, quantitatively, in the elimination of ethene.

Loss of methyl from ions $1 \mathrm{c}^{+\cdot}$ containing only one $\mathrm{CD}_{3}$ group reveals an apparently inverse kinetic isotope effect favouring the loss of $\mathrm{CD}_{3}{ }^{\circ}$ over that of $\mathrm{CH}_{3}{ }^{\circ}$ by a factor of 1.7. This value is surprisingly small, and the normal $70 \mathrm{eV}$ EI mass spectrum of 1c shows almost the same: here, $\left[1 \mathrm{c}-\mathrm{CD}_{3}\right] /\left[1 \mathrm{c}-\mathrm{CH}_{3}\right]=1.55$, whereas, in general, strongly energy-dependent isotope effects are observed. ${ }^{23}$ These inverse isotope effects clearly indicate the occurrence of a hidden hydrogen transfer in the rate-determining step of the overall rearrangement process, as has been demonstrated earlier for a number of radical cations of simple carbonyl compounds. ${ }^{4,7}$ Clearly, the data of ions $\mathbf{~ c}^{+\cdot}$ also show that no hydrogen exchange occurs between the two methyl groups. Finally, elimination of ethene from ions $\mathbf{1 c}^{+\bullet}$ takes place exclusively by loss of $\mathrm{C}_{2} \mathrm{H}_{2} \mathrm{D}_{2}$, suggesting, as will be confirmed later, the incorporation of two hydrogen atoms from each of the original methyl groups into the neutral fragment.

The fragmentation of metastable 2-ethyl-1,3-indandione ions $2 \mathrm{a}^{+}$is less clear. Interestingly, a minor part (about one-sixth) of the methyl loss produces $\mathrm{CH}_{2} \mathrm{D}^{\circ}$ radicals, again pointing to considerable rearrangement processes. Even more strikingly, the major fraction (up to two thirds) of the ethene fragment contains the label.
At first glance, these data appear surprising. It will be shown, however, that they are perfectly in line with an isomerization sequence which combines the two pairs of fast-interconverting isomers $1^{+\bullet} \rightleftharpoons 3^{+\cdot}$ and $2^{+\cdot} \rightleftharpoons 4^{+\cdot}$ via the slowly interconverting indandione ions $1^{+\cdot}$ and $2^{+\cdot}$.

\section{Five-step isomerization of 1,3-indandione radical cations}

The mechanism of the isomerization of the 1,3-indandione ions is shown in Scheme 4. Starting with the molecular radical cation of 2,2-dimethylindandione, $1^{+*}$, a series of consecutive 1,4- $\mathrm{H}, 1,2-\mathrm{C}$ and 1,2- $\mathrm{H}$ shifts leads to the enol radical cation $m$. These three steps correspond to those occurring in the radical cations of simple carbonyl species (Scheme $1, A \rightleftharpoons b \rightleftharpoons c \rightleftharpoons d$ ). From the kinetic isotope effect observed with ions $1 \mathbf{c}^{+}$, it is suggested that the first step, i.e. the 1,4-H shift $1^{+\cdot} \rightarrow k$, is rate determining. Both intermediates $l$ and $m$ should be more stable than the primarily formed distonic ion $k$, in line with the isotope effect observed. Nevertheless, there is evidence that the formation of ions $k$ is reversible (see below) and, in fact, the low energy dependence of the kinetic isotope effect points to the competition of the 1,4-H shift with other processes. The subsequent 1,2-C shift converts the five-membered $\beta$-distonic ion $k$ into the six-membered $\beta$-distonic ion $l$. With regard to the readily occurring rearrangement $\mathbf{1}^{+\cdot} \rightleftharpoons 3^{+\cdot}$ discussed above, this $1,2-\mathrm{C}$ shift should be at least as facile since it does not require full cleavage of the $\mathrm{C}(1)-\mathrm{C}(2)$ bond. 1,2-H shift in the ring-expanded ion $l$ subsequently leads to the enol radical cation $m$.

In the case of simple carbonyl compounds, the enol ion formed by the three-step isomerization sequence (cf. $d$ in Scheme 1) expels an alkyl radical to give a highly stable hydroxyallyl cation. This was expected in the 

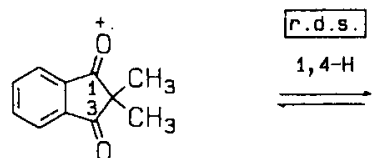

$1^{+}$

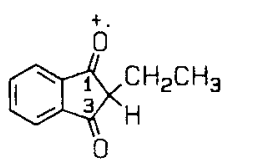

fast
$1,4-\mathrm{H}$

$2^{+}$<smiles>C=C=[SnH2]</smiles>

$o$<smiles>CC1(C)C(=O)c2ccccc2C1=O</smiles>

$\stackrel{1,2-C^{1}}{=}$<smiles>CC1CC(=O)c2ccccc2C1=O</smiles>

I

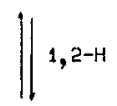<smiles>CC=CC1C(=O)c2ccccc2C1=O</smiles><smiles>C1=CCCCC1</smiles><smiles>CC1C=C(O)c2ccccc2C1=O</smiles>

$m$

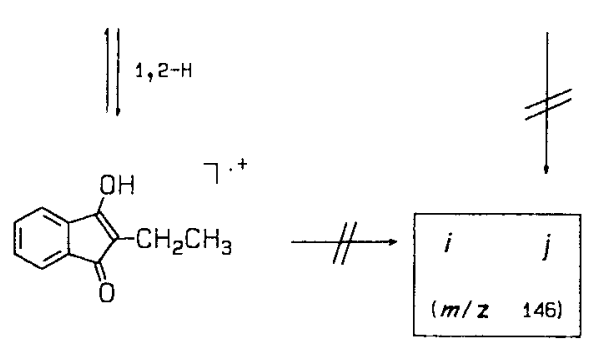

$p$

e $(m / z \quad 146)$

Scheme 4. Five-step isomerization of indandione ions $1^{+\bullet}$ and $2^{+\cdot}$

present case also; hence, ions $m$ appear prone to lose the methyl group generating ions $\left[\mathrm{M}-\mathrm{CH}_{3}\right]^{+}(\mathrm{m} / z$ 159) with the structure of $O$-protonated naphthoquinone $(j)$. Surprisingly, and although it would be in line with the labelling data, this process does not take place, as will be shown below by CID measurements on authentic reference ions. Instead of the fission of the external $\mathrm{C}-\mathrm{C}$ bond, the internal bond bearing the unprotonated carbonyl group is shifted to the adjacent carbon centre (i.e. to the original $\mathrm{C}^{\alpha}$ atom). ${ }^{24}$ The cleavage of the internal $\mathrm{C}-\mathrm{C}$ bond may be viewed as a first step of an electrocyclic (Cope) ring-opening reaction which does not reach completion because the system preferably undergoes re-contraction of the sixmembered ring by a reciprocal 1,2-C shift to give another $\beta$-distonic ion, $n$. This species represents the 1propylidene analogue of $k$. Finally, another $1,4-\mathrm{H}$ shift converts $k$ into the 'regular' molecular radical cation of 2-ethyl-1,3-indandione, $2^{+}$.

This whole sequence consists of five consecutive isomerization steps in a quasisymmetrical succession [there is no evidence for a degenerate proton shift from one carbonyl group to the other, e.g. in intermediate ion $m$ : the present data (cf. 1b and 1c, Table 2) exclude any hydrogen exchange involving the hydrogen atoms of the aromatic ring. In contrast, $O$-protonated benzaldehydes and phenones do undergo proton transfer to the aromatic ring $\left.{ }^{24}\right]$. It appears reasonable to assume that the 1,4-H shift involving the intramolecular hydrogen abstraction from a primary $\mathrm{C}-\mathrm{H}$ bond (i.e. $\mathbf{1}^{+\cdot} \rightarrow k$ ) is more energy-demanding than the reciprocal one involving a secondary $\mathrm{C}-\mathrm{H}$ bond (i.e. $2^{+\cdot} \rightarrow n$ ), rendering the former step rate determining. Moreover, the central 1,2H shift $(l \rightarrow m)$ should be energetically favourable because of the formation of a stable enol radical cation, and hence not be rate determining. However, since the 1,4- and 1,2-H shifts involve the hydrogen atoms from the same, disassembled methyl group, the isotope effect observed with $1 \mathbf{c}^{+*}$ does not allow one strictly to identify the rate-determining step of the overall isomerization sequence.

It may be noted that, in line with the isomerization steps outlined here, the $\beta$-distonic ion $n$ should be able to undergo a 1,2-H shift in competition with the $1,4-\mathrm{H}$ shift leading to $2^{+*}$. This would give rise to the enol radical cations of 2-ethyl-1,3-indandione, $p$ (Scheme 3). This process cannot be excluded (see below), and it has been considered as a channel leading to loss of the methyl radical. However, akin to the enol-type ions $m$, ions $p$ do not expel the methyl radical either, since the $\left[\mathrm{M}-\mathrm{CH}_{3}\right]^{+}$ions produced do not have the structure of protonated 2-methylene-1,3-indandione $i$ (see CID results discussed below).

The necessity for the five-step isomerization sequence follows compellingly from the fact that the branched, 2 -propylidene isomers $1^{+\cdot}$ and $3^{+\cdot}$ expel ethene along with the methyl radical. The labelling results agree completely with the isomerization mechanism. Regarding the 2,2-dimethyl-1,3-indandione structure of 1 as '2,2phthaloylpropane', the mechanism corresponds, in total, 

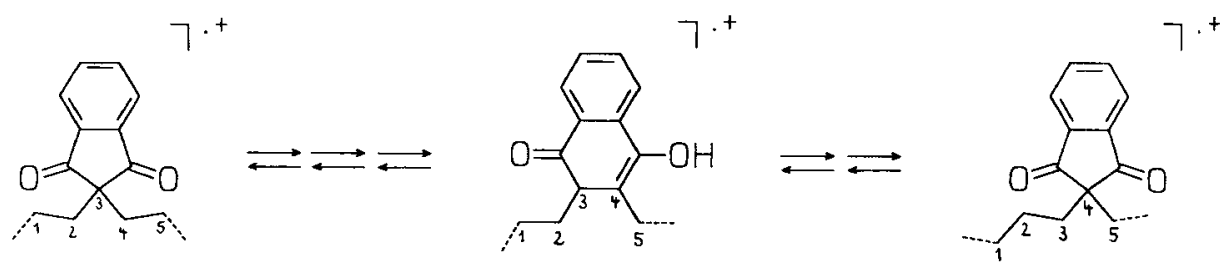

Scheme 5. 'Walk' isomerization of the (ionized) phthaloyl group along the aliphatic chain (e.g. positions 3 and 4).

to a 1,2-shift of the entire, ionized phthaloyl group to give the corresponding '1,1-phthaloylpropane' structure of 2 (Scheme 5). This, of course, requires that the ethene molecules eliminated from ions $1^{+*}$ retain the original $\mathrm{C}(2)$ carbon atom: in irct, ions $\mathbf{1 a}^{+\cdot}$ expel exclusively ${ }^{13} \mathrm{C}^{12} \mathrm{CH}_{4}$. Moreover, hey also retain two hydrogens from each of the origin 1 methyl groups: ions $1 \mathbf{c}^{+\cdot}$ expel $\mathrm{C}_{2} \mathrm{H}_{2} \mathrm{D}_{2}$ exclusively. Hence, the ionic fragment $e$ contains one hydrogen atom from the disassembled methyl group of $1^{+\cdot}$ and one from the other, intact group, which transfers that hydrogen atom in the course of the McLafferty reaction of ions $2^{+*}$.

The fragmentation of metastable 2-ethyl-1,3-indandione ions $2 \mathrm{a}^{+*}$ also corroborates the above interpretation and, beyond that, it reveals that all steps of the isomerization sequences are reversible. This follows from the fact that $\mathrm{CH}_{2} \mathrm{D}^{*}$ is lost from ions $\mathbf{2 a}^{+\cdot}$ with $\left[2-\mathrm{CH}_{2} \mathrm{D}\right]^{+} /\left[2-\mathrm{CH}_{3}\right]^{+}=15: 85$. The observed expulsion of the labelled methyl group requires a minor part of ions $2 \mathrm{a}^{+\cdot}$ to be converted, via the full five-step sequence, into isomer $\mathbf{1 d}^{+}$bearing a $\mathrm{CH}_{2} \mathrm{D}$ group (Scheme 6). This 'symmetrized' isotopomer may then undergo reversion to either the original ions $2 \mathbf{a}^{+\cdot}$ or to ions $\mathbf{2 b}^{+}$containing the label in the methylene group, or, still alternatively, to ions $2 \mathrm{c}^{+}$bearing it in the methyl group. The latter intermediate is then rearranged to the corresponding propylidenephthalide ion from which $\mathrm{CH}_{2} \mathrm{D}^{\circ}$ is expelled, eventually. Again, the 1,4-H shift $k \rightleftharpoons 1^{+}$seems to be rate determining within the whole isomerization process since only a minor fraction of ions $2 \mathbf{a}^{+\cdot}$ reach the 'point of return' (i.e. $1 \mathbf{d}^{+\cdot}$ ).

Moreover, the experimental ratio of ethene losses, $\left[2-\mathrm{C}_{2} \mathrm{H}_{3} \mathrm{D}\right]^{+} /\left[2-\mathrm{C}_{2} \mathrm{H}_{4}\right]^{+} \approx 66: 34$, obtained after correction for the contribution of $\mathrm{CO}$ elimination, is

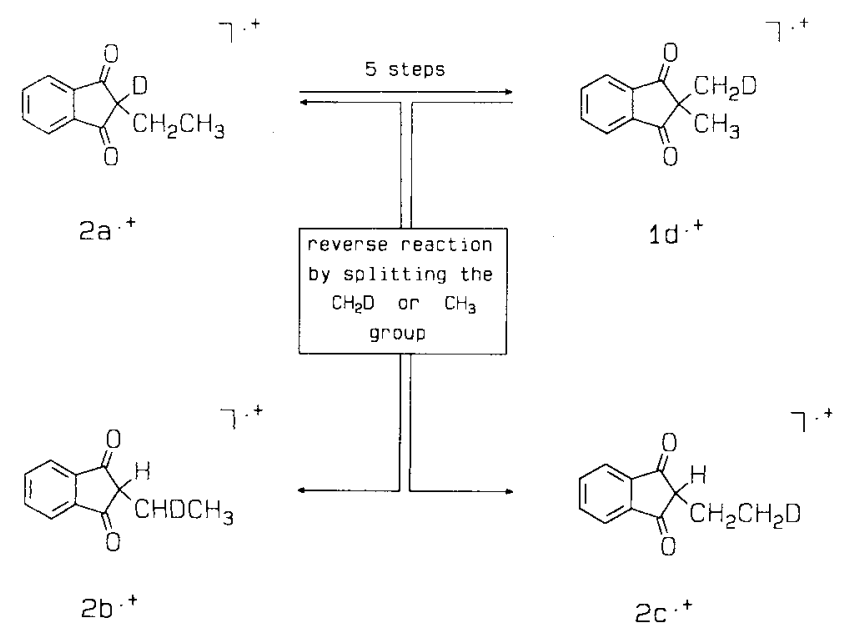

Scheme 6. Conversion of ions $2 a^{+*}$ to isotopomers $2 b^{+*}$ and $2 \mathrm{c}^{+\cdot}$ nearly identical with the value $(2: 1)$ calculated for the complete equilibration of $2^{+\cdot}$ and $1^{+\cdot}$ (Scheme 4). By accident, however, the same ratio is expected for an equilibration involving only a limited section of this route, e.g. $2^{+\cdot} \rightleftharpoons n \rightleftharpoons m \rightleftharpoons l$ (or $\mathbf{2}^{+\cdot} \rightleftharpoons n \rightleftharpoons m \rightleftharpoons l \rightleftharpoons k$ ). This prevents the observability of a kinetic isotope effect even if the rate-limiting step $k \rightleftharpoons 1^{+}$were to be included in the overall interconversion. Finally, the reversible sequence $2^{+\cdot} \rightleftharpoons n \rightleftharpoons p$, involving a $1,2-\mathrm{H}$ shift comparable to that in $l \rightleftharpoons m$, would lead to the observed ratio for ethene loss from $2 \mathbf{a}^{+\cdot}$ also. (The fact that the hypothetical intermediate $p$ does not undergo methyl loss, as will be shown below, does not exclude it from the overall multi-step isomerization process.) In spite of these ambiguous mechanistic implications, the predominant loss of $\mathrm{C}_{2} \mathrm{H}_{3} \mathrm{D}$ from $2^{+\cdot}$ corroborates the conclusion drawn from the partial loss of $\mathrm{CH}_{2} \mathrm{D}^{-}$from the same isotopomer, that is, reversibility of the isomerization process $1^{+\cdot} \rightleftharpoons 2^{+\bullet}$.

\section{Higher homologues}

The mass spectrometric fragmentation of 2-ethyl-2methyl-1,3-indandione (5) and 2,2-diethyl-1,3-indandione (6) corroborates the multi-step rearrangement mechanism proposed in Scheme 4 . In the $70 \mathrm{eV}$ mass spectra of these homologues, ions $\left[\mathrm{M}-\mathrm{CH}_{3}\right]^{+}$and $\left[\mathrm{M}-\mathrm{C}_{2} \mathrm{H}_{5}\right]^{+}$, respectively, are represented by the base peaks (Fig. 3). According to the results discussed above, these fragments are due to rearrangement processes rather than to simple $\mathrm{C}-\mathrm{C}$ bond cleavages. Thus, the MIKE spectra of ions $5^{+\cdot}$ and $6^{+\cdot}$ (Table 3) exhibit again competitive loss of alkyl and alkene neutrals (along with some carbon monoxide). Here again, the most remarkable feature is the elimination of higher alkenes, viz. $\mathrm{C}_{3} \mathrm{H}_{6}$ from $5^{+\cdot}(6 \%)$ and, in the case of $6^{+\cdot}$, $\mathrm{C}_{3} \mathrm{H}_{6}(36 \%)$ and even a small amount of $\mathrm{C}_{4} \mathrm{H}_{8}$. These fragmentations correspond to the loss of $\mathrm{C}_{2} \mathrm{H}_{4}$ from $\mathbf{1}^{+}$, with their relative rates reflecting the preferred abstraction of a secondary over a primary hydrogen atom during the various $1,4-\mathrm{H}$ shifts. Hence, the loss of $\mathrm{C}_{4} \mathrm{H}_{8}$ (and also of the 'McLafferty +1 ' neutral $\mathrm{C}_{4} \mathrm{H}_{7}{ }^{\circ}$ ) from $6^{+\cdot}$ unequivocally requires the occurrence of two successive and complete ring expansion-recontraction sequences, again suggesting a mutual interconversion of the isomeric 1,3-indandione radical ions $\left[\mathbf{M}_{(1)}^{+.}, \mathbf{M}_{(2)}^{+.}\right.$, etc.; cf. Scheme 5).

These results corroborate the finding that the ionized phthaloyl moiety of 1,3-indandiones may act as a bidentate ligand migrating along the aliphatic chain prior to fragmentation (Scheme 5). In fact, the protonated phthaloyl group generated recurrently represents a special case of protonated function groups $\mathrm{XH}^{+}$, such 


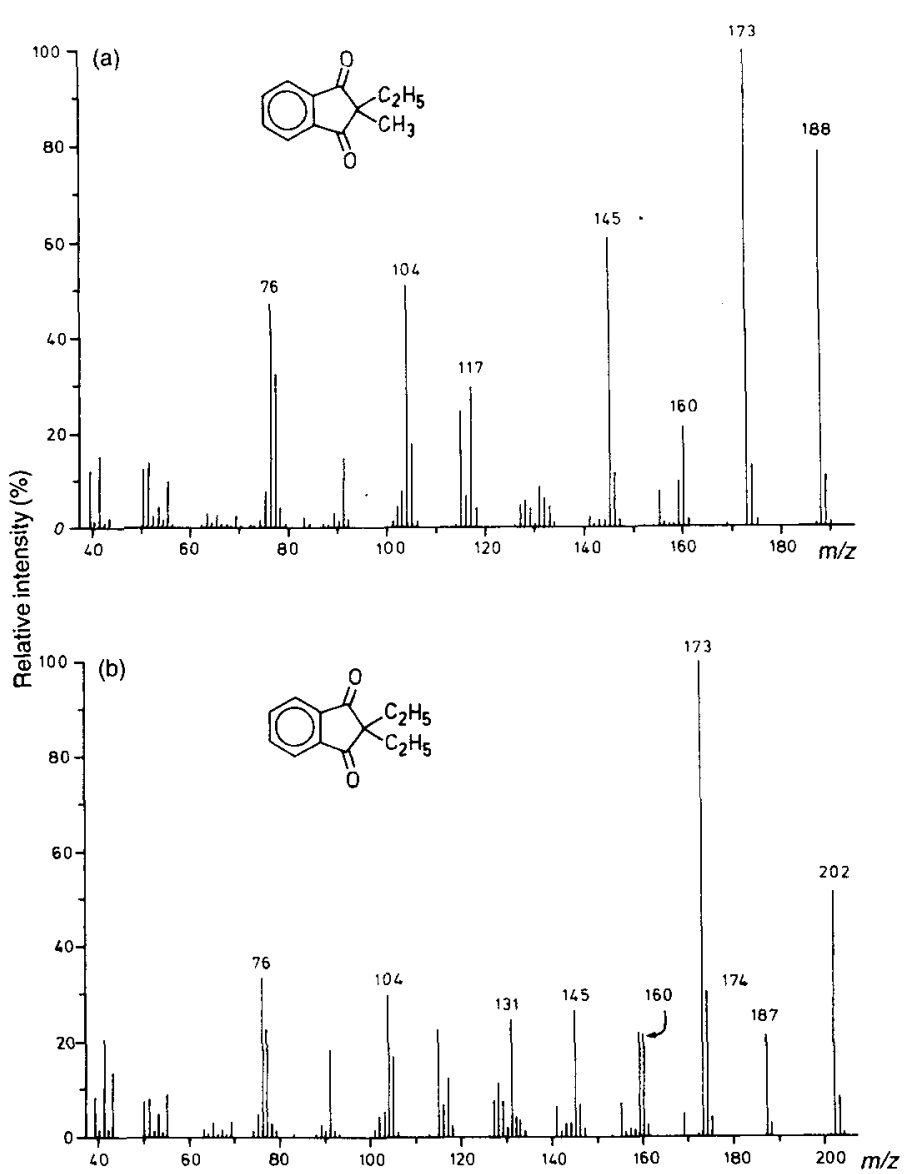

Figure 3. $70 \mathrm{eV}$ El mass spectra of (top) 2-ethyl-2-methyl-1,3indandione (5) and (bottom) 2,2-diethyl-1,3-indandione (6).

as $=\mathrm{COH}^{+},-\mathrm{C}(\mathrm{OH})_{2}{ }^{+},-\mathrm{NH}_{3}{ }^{+}$or $-\mathrm{OH}_{2}{ }^{+},{ }^{25}$ which are known to undergo facile 1,2-shifts at a $\mathrm{C}_{2}$ unit bearing a radical $\beta$ to the $\mathrm{XH}^{+}$group.

\section{Structure of $\left[\mathrm{M}-\mathrm{CH}_{3}\right]^{+}$ions}

In contrast to the stable molecular ions of the 1,3indandiones 1 and 2 (cf. Fig. 2), the corresponding frag-

Table 3. Fragmentation of the metastable molecular ions of 2-ethyl-2methyl-1,3-indandione (5) and 2,2-diethyl1,3-indandione (6) (MIKE spectra, $\Sigma \%$ )

\begin{tabular}{lcr}
\multicolumn{1}{c}{ Loss of } & 5 & 6 \\
$\mathrm{CH}_{3}{ }^{\circ}$ & 48.0 & 1.4 \\
$\mathrm{H}_{2} \mathrm{O}$ & 0.2 & 0.3 \\
$\mathrm{C}_{2} \mathrm{H}_{4}, \mathrm{CO}^{\circ}$ & 46.2 & 18.4 \\
$\mathrm{C}_{2} \mathrm{H}_{5}{ }^{\circ}$ & - & 42.5 \\
$\mathrm{C}_{3} \mathrm{H}_{6}$ & 5.8 & 35.7 \\
$\mathrm{C}_{4} \mathrm{H}_{7}$ & - & 1.0 \\
$\mathrm{C}_{4} \mathrm{H}_{8}$ & - & 0.8 \\
Loss of CO represent minor \\
contributions, as indicated by a \\
broadened foot of the [M \\
-28] ${ }^{+\cdot}$ signals. \\
\hline
\end{tabular}

ment ions $\left[1-\mathrm{CH}_{3}\right]^{+}$and $\left[2-\mathrm{CH}_{3}\right]^{+}$exhibit identical MIKE and CID-MIKE spectra [Fig. 4(a) and (b)]. This is in line with the fact that, owing to their higher internal energies, the unstable $\mathrm{M}^{+\cdot}$ ions may undergo relatively fast interconversion $1^{+\cdot} \rightleftharpoons 2^{+\cdot}$, prior to fragmentation. Not surprisingly, the CID-MIKE spectra of the $\left[\mathrm{M}-\mathrm{CH}_{3}\right]^{+}$ions from the isomeric alkylidenephthalides 3 and 4 [Fig. $4(\mathrm{c})$ and (d)] are mutually identical and closely similar to those of 1 and 2 . Therefore, in all four cases, the loss of $\mathrm{CH}_{3}{ }^{\circ}$ leads to $\mathrm{C}_{10} \mathrm{H}_{7} \mathrm{O}_{2}{ }^{+}$ions of the same structure (or mixture of structures).

As discussed above, the radical cations of simpler carbonyl compounds undergo a three-step isomerization prior to alkyl loss, giving rise to the formation of particularly stable 1-hydroxyallyl ions (Scheme $1, A \rightarrow C$ ). Therefore, in the case of the 1,3-indandione ions studied here, it appeared likely that the $\mathrm{CH}_{3}{ }^{\cdot}$ radical is lost from the distonic ion $m$ (Scheme 4). In fact, the [M $\left.-\mathrm{CH}_{3}\right]^{+}$ions formed via $m$ should have the structure of protonated naphthoquinone $(j)$, and hence be fairly stable.

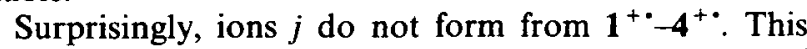
follows unequivocally from the CID-MIKE spectra of $\mathrm{C}_{10} \mathrm{H}_{7} \mathrm{O}_{2}{ }^{+}$ions generated by either gas-phase protonation $\left[\mathrm{CI}\left(\mathrm{CH}_{4}\right)\right]$ of 1,4-naphthoquinone 7 or by EI-
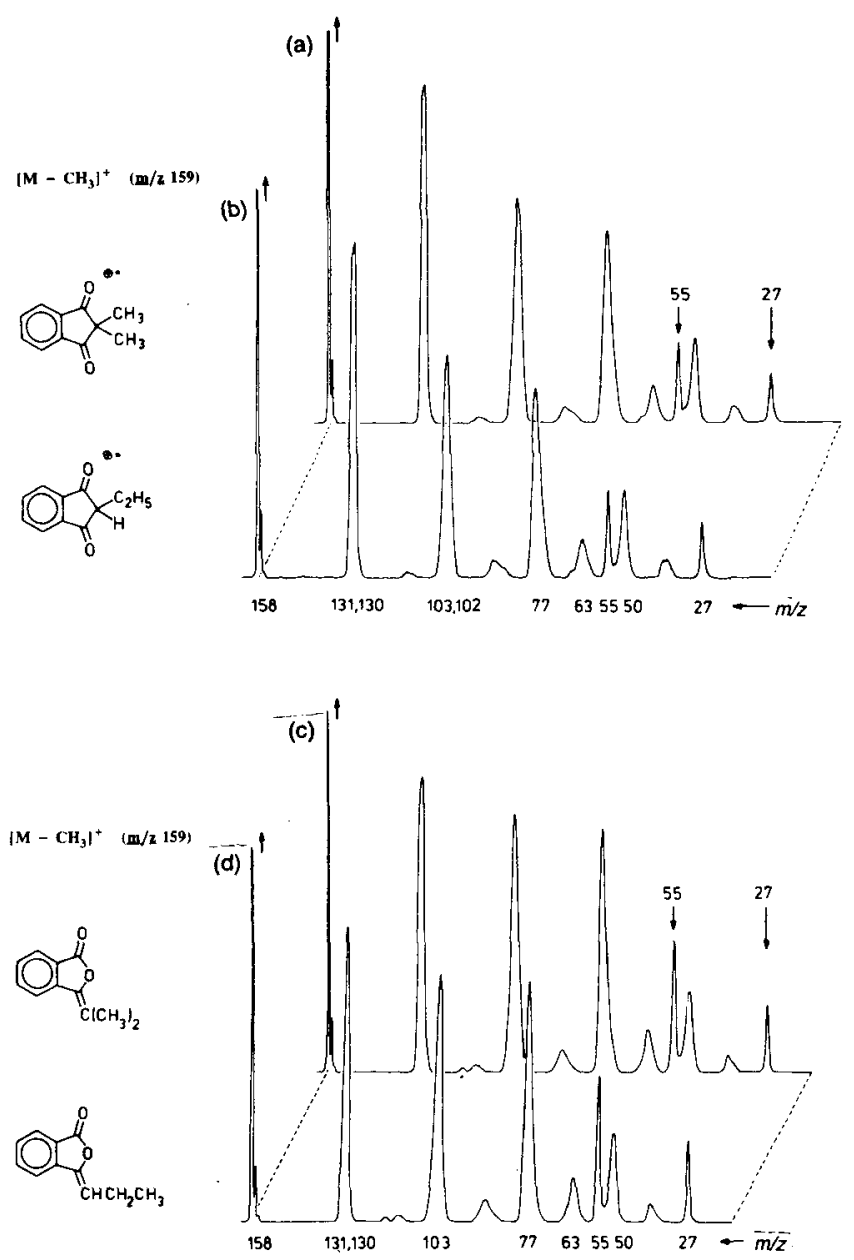

Figure 4. CID-MIKE spectra of the $\left[\mathrm{M}-\mathrm{CH}_{3}\right]^{+}$ions $(m / z 159)$ from (top) 1,3-indandiones 1 and 2 and (bottom) 3methylenephthalides 3 and 4. 


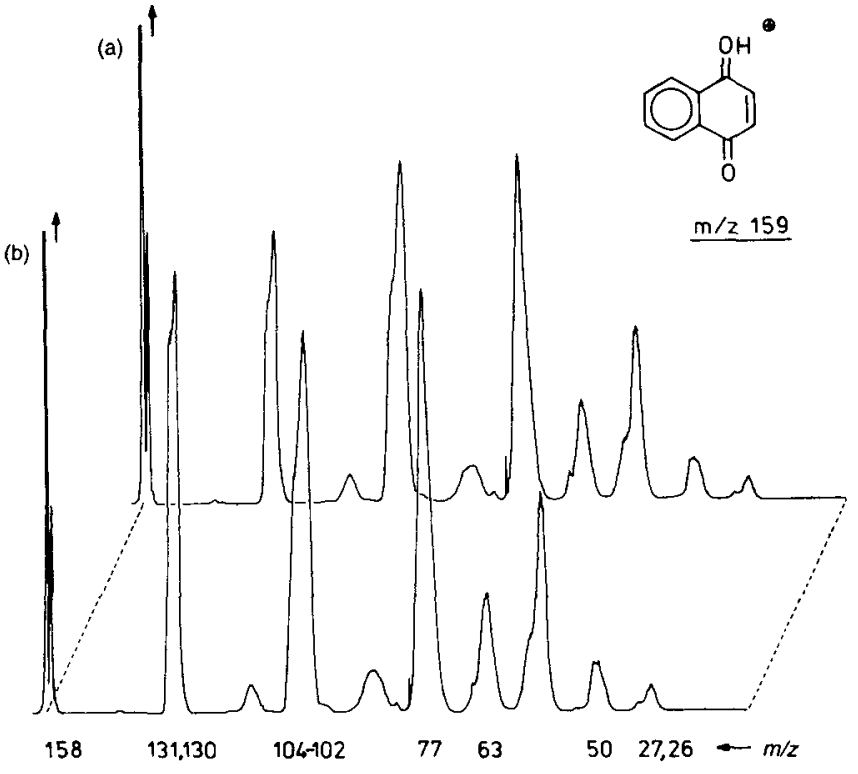

Figure 5. CID-MIKE spectra of $\mathrm{C}_{10} \mathrm{H}_{7} \mathrm{O}^{+}(\mathrm{m} / \mathrm{z}$ 159) ions $[7+\mathrm{H}]^{+}($top $)$and $\left[8-\mathrm{CH}_{3}\right]^{+}$(bottom) (cf. Scheme 7).

induced methyl loss from the quinol 8 [Fig. 5(a) and (b), Scheme 7]. While the CID spectra of ions $[7+\mathrm{H}]^{+}$ and $\left[8-\mathrm{CH}_{3}\right]^{+}(\equiv j)$ are identical, they differ from those of the $\left[\mathrm{M}-\mathrm{CH}_{3}\right]^{+}$ions from $1-4$ by the almost complete lack of the signals at $m / z 55$ and 27 . Instead, the contribution at $m / z 104$ is nearly absent in the latter spectra but is pronounced in the spectra of ions $j$. Hence, clearly, the loss of $\mathrm{CH}_{3}$ from the interconverting ions $1^{+\cdot}-4^{+\cdot}$ does not proceed via the protonated naphthoquinone intermediates $j$.

As a further possibility, methyl loss from ions $1^{+\cdot}-4^{+\cdot}$ could occur via the enol ions $p$ formed via the distonic ions $n$ (Scheme 4). While enol ions $m$ and $p$ should have similar heats of formation, loss of $\mathrm{CH}_{3}{ }^{\circ}$ from the latter appears less facile since the resulting $\mathrm{C}_{10} \mathrm{H}_{7} \mathrm{O}_{2}{ }^{+}$ion (i) should be less stable than the isomer $j$. In fact, the corresponding neutral precursor, 2-methylene-1,3-indandione, is not stable in the condensed phase. ${ }^{26}$ Nevertheless, the sequence $n \rightleftharpoons p \rightarrow i$ appears more probable an exit channel from the interconverting

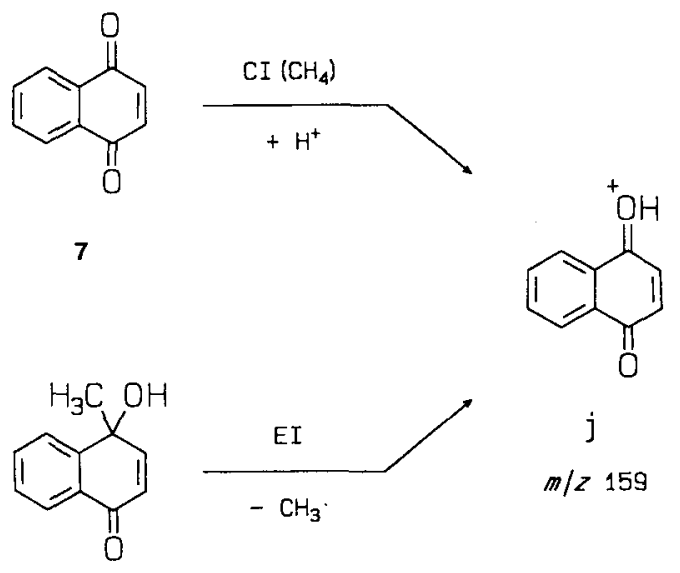

8

Scheme 7

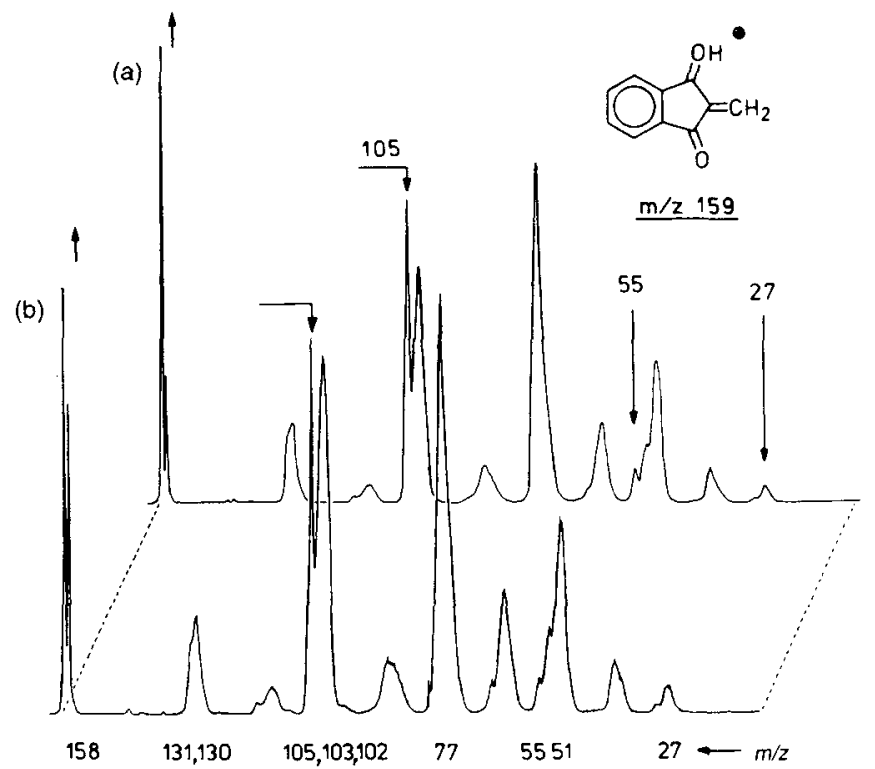

Figure 6. CID-MIKE spectra of $\mathrm{C}_{10} \mathrm{H}_{7} \mathrm{O}^{+}(\mathrm{m} / \mathrm{z}$ 159) ions $[9-\text { styrene - benzyl }]^{+}$(top) and $\left[10-\mathrm{C}_{5} \mathrm{H}_{5}\right]^{+}$(bottom) (cf. Scheme 8).

system $1^{+\cdot}-4^{+\cdot}$ than the loss of $\mathrm{CH}_{3}$ from the distonic ion intermediate $k$ (Scheme 4).

However, ions $i$ do not form either. Again, the CIDMIKE spectra of this species [Fig. 6(a) and (b)], generated by EI-induced fragmentation of either 2,2-bis $(\beta$ phenylethyl)-1,3-indandione (9) or '5,5-phthaloylnorbornene' (10) (Scheme 8), is clearly distinct from those obtained for the $\left[\mathrm{M}-\mathrm{CH}_{3}\right]^{+}$ions of $1-4$. In addition to other differences, ions at $\mathrm{m} / z 55$ and 27 occur with very minor abundances, but a pronounced peak at $m / z$ 105 is observed in contrast to all other CID spectra of the $\mathrm{C}_{10} \mathrm{H}_{7} \mathrm{O}_{2}{ }^{+}$ions studied here. It is therefore obvious that methyl loss from ions $1^{+\cdot}-4^{+\cdot}$ does not give rise to the formation of $O$-protonated 2-methylene-1,3-indandione $i$. Hence neither enol ions $p$ nor in line with previous findings, ${ }^{4}$ distonic ions $k$ represent direct precursors to the $\left[\mathrm{M}-\mathrm{CH}_{3}\right]^{+}$ions of $1-4$.

In summary, both ions $i$ and $j$ have been excluded experimentally as $\left[\mathrm{M}-\mathrm{CH}_{3}\right]^{+}$ions of $1^{+\cdot}-4^{+\cdot}$, and other $\mathrm{C}_{10} \mathrm{H}_{7} \mathrm{O}_{2}{ }^{+}$structures, in particular ions $g$ and $h$

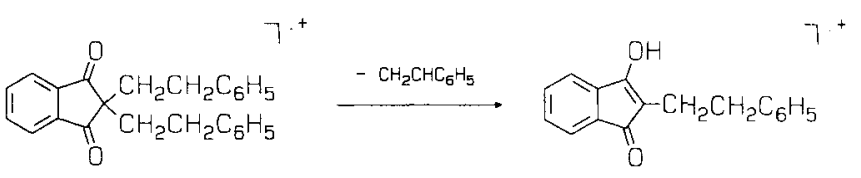

9

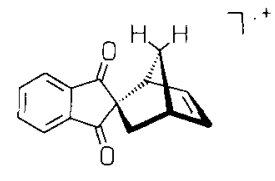

10
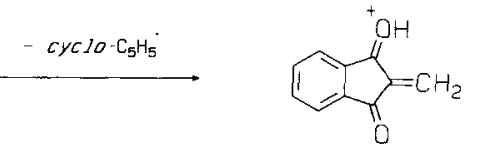

i 
(Scheme 3), are highly unreasonable candidates by intuition. Ion $f$, however, represents a convincingly good candidate since it may be formed by simple and favourable allylic $\mathrm{C}-\mathrm{C}$ bond cleavage of 1propylidenephthalide ions $4^{+\bullet}$. The cyclic $\alpha$-oxybenzyl moiety bearing a stabilizing $\alpha$-vinyl substituent appears to be a thermochemically favourable structure, in spite of the somewhat destabilizing vinylogous orthocarbonyl group integrated within the lactone ring. On the other hand, this qualitative consideration also accounts for ions $i$ and $j:$ in both cases, the oxybenzyl carbocationic centre is flanked by a vinyl substituent and a vinylogous ortho-carbonyl group. In view of the experimental facts, it follows that the lactone moiety in ions $f$ may exert additional stabilization, whereas the unprotonated carbonyl group in ions $j$ displays a twofold vinylogous destabilization. In ions $i$, finally, the unfavourable strain of three exocyclic $\pi$ bonds should considerably destabilize the structure.

As shown above, the formation of ions $\mathrm{C}_{3} \mathrm{H}_{3} \mathrm{O}^{+}(\mathrm{m} / \mathrm{z}$ 55) and $\mathrm{C}_{2} \mathrm{H}_{3}{ }^{+}(m / z 27)$ is a characteristic feature for $\mathrm{C}_{10} \mathrm{H}_{7} \mathrm{O}_{2}{ }^{+}$cations $f$. It is obvious that these fragments originate from the acryloyl moiety of structure $f$, which is expelled upon CID as shown in Scheme 9. In the case of ions $i$, the (at least formally) complementary process takes place, that is, expulsion of the elements of $\mathrm{C}_{3} \mathrm{H}_{2} \mathrm{O}$ (as $\mathrm{CH}_{2}=\mathrm{C}=\mathrm{C}=\mathrm{O}$ or, more probably, as $\mathrm{C}_{2} \mathrm{H}_{2}$ and $\mathrm{CO}$ ). Obviously, a similar cleavage process is not possible in ions $j$.

Inspection of the CID spectra of the ${ }^{2} \mathrm{H}$ - and ${ }^{13} \mathrm{C}$ labelled $[\mathrm{M}-\text { methyl }]^{+}$ions generated from indandiones 1a-c and 2 a corroborates the origin of the $\mathrm{m} / \mathrm{z}$ 55 and 27 peaks. Figure 7 shows the CID spectrum of ions $\left[2 \mathbf{a}-\mathrm{CH}_{3}\right]^{+}\left(f^{\prime}\right.$ and $f^{\prime \prime}$, Scheme 10$)$, for example, in which both of these signals are shifted cleanly by $1 \mathrm{u}$. Hence the chemistry of the various $\mathrm{C}_{10} \mathrm{H}_{7} \mathrm{O}_{2}{ }^{+}$cations studied here appears to be highly interesting in itself.

Referring to the starting point of this investigation, however, it appears striking to note that the $\mathrm{C}_{3} \mathrm{H}_{3}{ }^{+}$ $(\mathrm{m} / z 55)$ ions are just one of the few criteria which allow a distinction, from the standard $70 \mathrm{eV}$ spectra of $1-4$ (Fig. 1), between the branched and the unbranched 1,3indandione and methylenephthalide isomers.
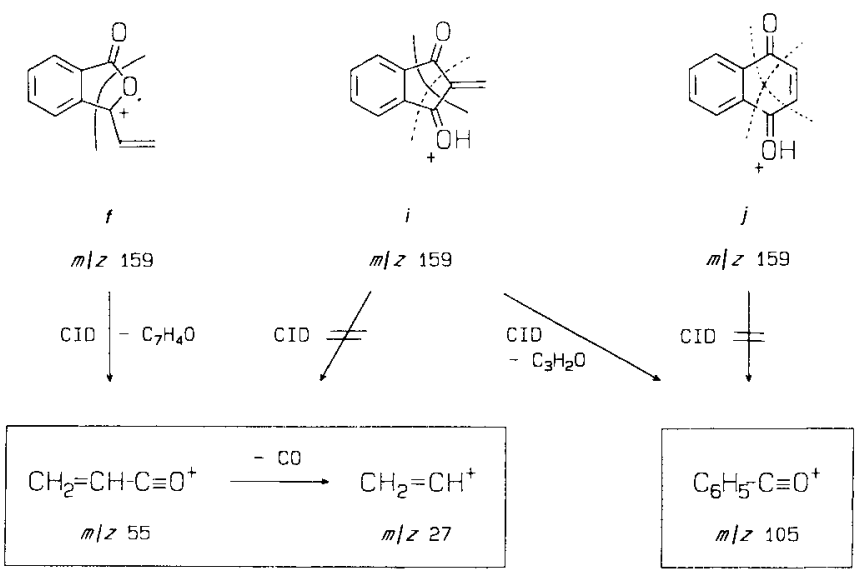

Scheme 9. Specific CID processes of $\mathrm{C}_{10} \mathrm{H}_{7} \mathrm{O}^{+}(m / 2159)$ ions $f$, $i$ and $j$.

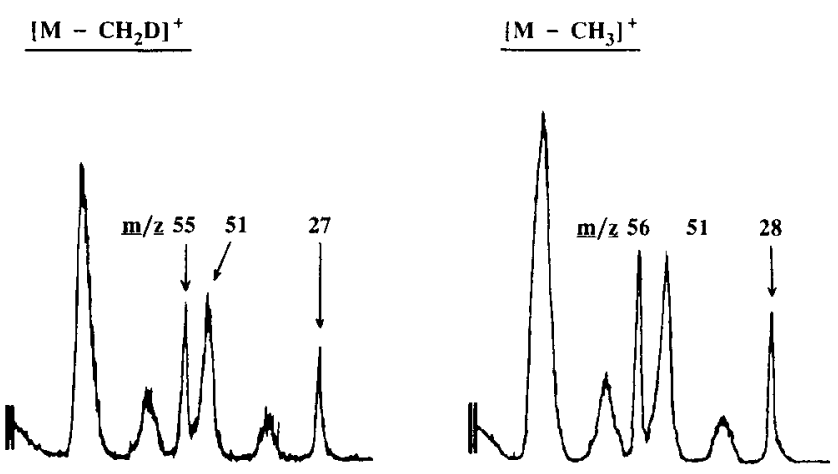

Figure 7. Comparison of the partial CID-MIKE spectra of ions $\left[\mathrm{M}-\mathrm{CH}_{2} \mathrm{D}\right]^{+}(m / 2159)$ and $\left[\mathrm{M}-\mathrm{CH}_{3}\right]^{+}(m / 2160)$ from $2 \mathrm{a}$ (cf. Scheme 10 and Fig. 4).
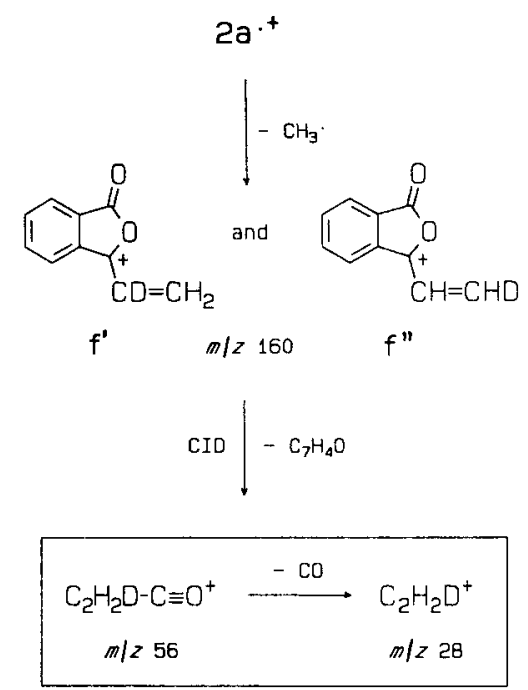

Scheme 10

\section{CONCLUSION}

The molecular cations of simple 2-alkyl-substituted 1,3indandiones and allied 3-alkylidenephthalides (1-4, 5 and 6) undergo a complex isomerization process including up to seven consecutive steps prior to expulsion of $\mathrm{CH}_{3}{ }^{-}$and $\mathrm{C}_{2} \mathrm{H}_{4}$, as illustrated in Scheme 11 . In contrast to simpler radical cations of carbonyl compounds, the former fragmentation does not take place from an ionized enol intermediate but rather from the (unbranched) $n$-propylidenephthalide isomer. In addition to the readily occurring 1,3 -indandione ${ }^{+\cdot} \rightleftharpoons 3$ methylenephthalide ${ }^{+}$isomerization, the overall rearrangement process includes a five-step interconversion of the radical cations of 1,3-indandiones, which may be generalized, in its literal sense, as a multi-step migration of the ionized, 'bipedal' phthaloyl group along a (neutral) polymethylene chain. In conclusion, this study is regarded as an ample demonstration of the chemical reasoning in the apparently complex behaviour of organic radical cations in the gas phase. 


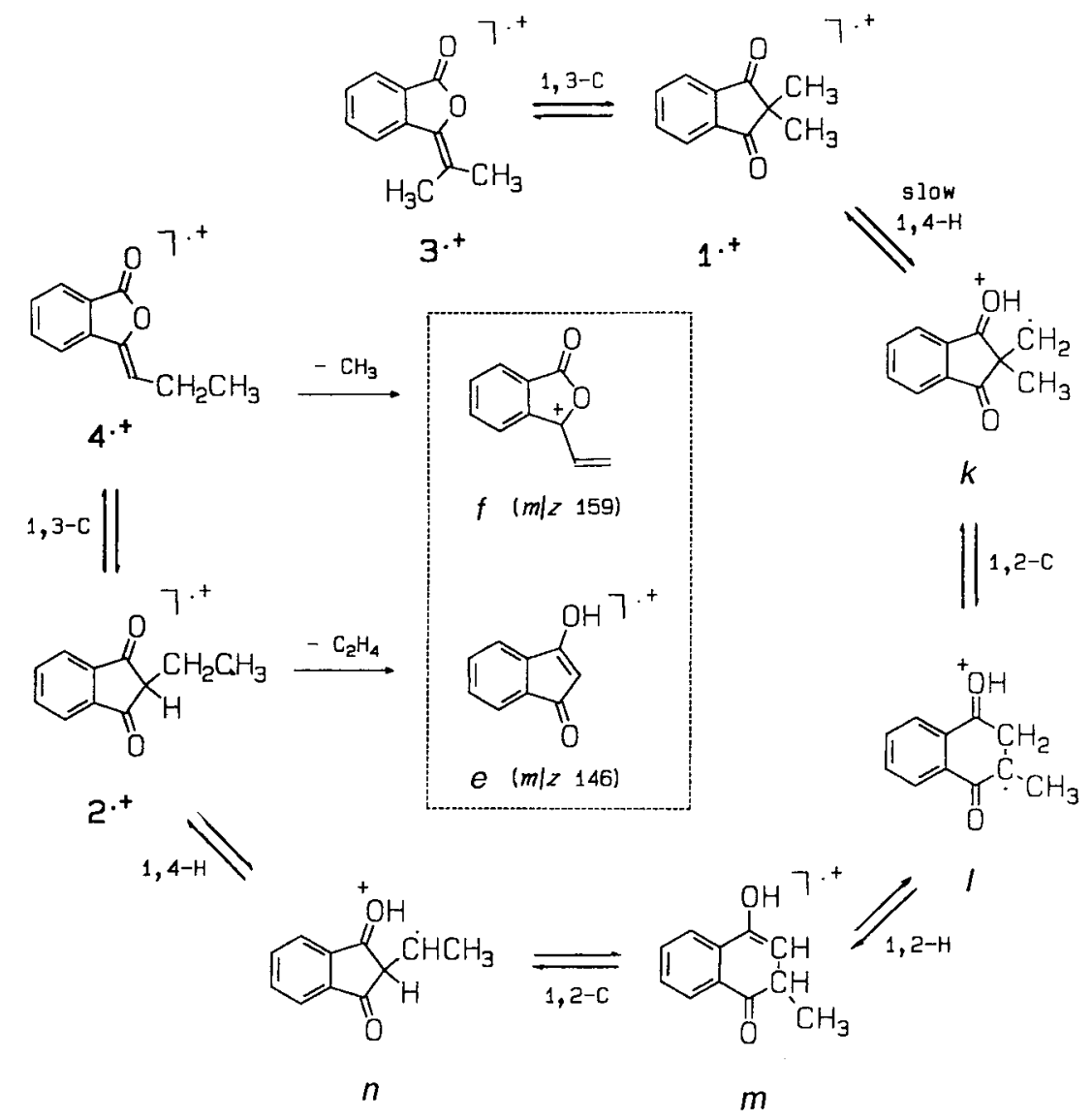

Scheme 11. Multi-step isomerization and primary fragmentation processes of the 1,3 -indandione-3-methylenephthalide system $1^{+\cdot-4^{+}}$

\section{EXPERIMENTAL}

EI mass spectra $(70 \mathrm{eV})$ were measured with a Finnigan MAT 311 A double-focusing instrument, electron impact (EI) and chemical ionization (CI) MIKE and CID-MIKE spectra were obtained with a Vacuum Generators ZAB-2F double-focusing mass spectrometer equipped with a magnetic sector followed by the electric one. The samples were introduced via the direct inlet probes without additional heating; ion source conditions (EI), electron energy $70 \mathrm{eV}$, trap current $100 \mu \mathrm{A}$, accelerating voltage $6 \mathrm{kV}$, source temperature $180^{\circ} \mathrm{C}$, nominal source pressure $10^{-4} \mathrm{~Pa} ;(\mathrm{CI})$, reagent gas methane (Matheson, stated purity $>99.95 \%$ ), electron energy $100 \mathrm{eV}$, emission current $500 \mu \mathrm{A}$, accelerating voltage $6 \mathrm{kV}$, source temperature $180^{\circ} \mathrm{C}$, nominal source pressure $0.01 \mathrm{~Pa}$.

High-resolution measurements were performed with a Finnigan MAT 311 A double-focusing mass spectrometer at a resolving power of $m / \Delta m \approx 15000$. For comparison, the measurements were repeated with a Bruker-Spectrospin CMS 47 Fourier transform ion cyclotron resonance (FT-ICR) mass spectrometer at $m$ / $\Delta m \approx 55000$, showing a ratio of $\left[\mathrm{M}-\mathrm{C}_{2} \mathrm{H}_{4}\right]^{+\cdot} /[\mathrm{M}$ $-\mathrm{CO}^{+\cdot}=80: 20$.

\section{Compounds}

2,2-Dimethyl-1,3-indandione (1), 2.2-bis([[ $\left.{ }^{13} \mathrm{C}\right]$ methyl)1,3-indandione (1a) and 2,2-bis([ $\left[\mathrm{D}_{3}\right]$ methyl)-1,3- indandione (1) were prepared by potassium fluoride on Celite (KF/Celite)-assisted alkylation of 1,3-indandione (Merck-Schuchardt) with $\mathrm{CH}_{3} \mathrm{I},{ }^{13} \mathrm{CH}_{3} \mathrm{I}$ (MSD Isotopes, $99 \%{ }^{13} \mathrm{C}$ ) or $\mathrm{CD}_{3} \mathrm{I}$ (Janssen, >99\% D), respectively, according to a procedure given by Bloch and Orvane. ${ }^{26}$ Purity of the compounds was checked by mass and ${ }^{1} \mathrm{H}$ NMR spectrometry. 1: ${ }^{1} \mathrm{H}$ NMR $(80$ $\left.\mathrm{MHz}, \mathrm{CDCl}_{3}\right), \delta(\mathrm{ppm}) 1.30\left(\mathrm{~s}, 6 \mathrm{H}, \mathrm{CH}_{3}\right), 7.94$ (centred AA'BB' $^{\prime}$ spin system, $4 \mathrm{H}$; $\left.\mathrm{H}^{\mathrm{ar}}\right)$. 1a: ${ }^{1} \mathrm{H}$ NMR $(80 \mathrm{MHz}$, $\mathrm{CDCl}_{3}$ ), $\delta$ (ppm) 1.3 (residual ${ }^{12} \mathrm{CH}_{3}<4 \%$ ), (centred $\mathrm{AA}^{\prime} \mathrm{BB}^{\prime}$ spin system, $4 \mathrm{H} ; \mathrm{H}^{\mathrm{ar}}$ ). $1 \mathrm{~b}:{ }^{1} \mathrm{H}$ NMR $(80 \mathrm{MHz}$, $\left.\mathrm{CDCl}_{3}\right), \delta(\mathrm{ppm}) 1.3$ (residual $\mathrm{CHD}_{2}<1 \%$ ), 7.93 (centred $\mathrm{AA}^{\prime} \mathrm{BB}^{\prime}$ spin system, $4 \mathrm{H} ; \mathrm{H}^{\text {ar }}$ ); MS (EI, $70 \mathrm{eV}$ ) $\left\{\left[D_{6}\right]-M^{+}\right\}>97 \%$. 2-Methyl-2-([D $]$ methyl)-1,3indandione (1c) was obtained in the same way ${ }^{26}$ starting from 2-methyl-1,3-indandione ${ }^{27}$ and $\mathrm{CD}_{3} \mathrm{I}$. ${ }^{1} \mathrm{H}$ NMR $\left(300 \mathrm{MHz}_{2} \mathrm{CDCl}_{3}\right), \delta(\mathrm{ppm}) 1.31\left(\mathrm{~s}, 3 \mathrm{H} ; \mathrm{CH}_{3}\right), 7.87$ and $8.00\left(\mathrm{AA}^{\prime} \mathbf{B B}^{\prime}\right.$ spin system, $\left.4 \mathrm{H} ; \mathrm{H}^{\mathrm{ar}}\right)$; MS (EI, $\left.70 \mathrm{eV}\right)$ $\left\{\left[\mathrm{D}_{3}\right]-\mathrm{M}^{+\bullet}\right\}>98 \%$. 2-Ethyl-1,3-indandione (2) was prepared as described in the literature. ${ }^{27}$ For the synthesis of 2-[D]-2-ethyl-1,3-indandione (2a), $0.55 \mathrm{~g} \mathrm{(3.0}$ mmol) of 2 were reacted in a stoppered bulb with $5.0 \mathrm{~g}$ $(0.25 \mathrm{~mol})$ of $\mathrm{D}_{2} \mathrm{O}(99.5 \% \mathrm{D}$, Merck) containing $0.5 \mathrm{~g}$ of $30 \% \mathrm{DCl}$ (prepared from $\mathrm{PCl}_{5}$ and $\mathrm{D}_{2} \mathrm{O}$ ) at $90^{\circ} \mathrm{C}$ overnight. ${ }^{1} \mathrm{H}$ NMR (250 MHz, $\left.\mathrm{CDCl}_{3}\right), \delta$ (ppm) 0.98 (t, $\left.{ }^{3} J=7.5 \mathrm{~Hz}, 3 \mathrm{H} ; \mathrm{CH}_{3}\right), 2.02\left(\mathrm{q},{ }^{3} J=7.5 \mathrm{~Hz}, 2 \mathrm{H}\right.$; $\left.\mathrm{CH}_{2}\right), 7.83$ and $7.98\left(\mathrm{AA}^{\prime} \mathrm{BB}^{\prime}\right.$ spin system, $\left.4 \mathrm{H} ; \mathrm{H}^{\mathrm{ar}}\right) ; \mathrm{MS}$ (EI, $70 \mathrm{eV})\left\{\left[\mathrm{D}_{1}\right]-\mathrm{M}^{+\cdot}\right\}>94 \%$.

3-Isopropylidenephthalide (3) and 3-(n-propylidene)phthalide (4) were synthesized from phthalic anhydride 
and butyric or isobutyric anhydride, respectively, as described in the literature. ${ }^{28}$

2-Ethyl-2-methyl-1,3-indandione (5) and 2,2-diethyl-1, 3 -indandione (6) were synthesized from 2 and the corresponding alkyl iodide as described in the literature. ${ }^{26}$ The indandiones were purified by Kugelrohr distillation $\left[0.1\right.$ mbar $\left(1\right.$ bar $\left.\left.=10^{5} \mathrm{~Pa}\right)\right]$ and recrystallization from $n$-hexane. 5: m.p. $46-47^{\circ} \mathrm{C}$ (lit. ${ }^{8 b}$ m.p. $46-47.5^{\circ} \mathrm{C}$ ); MS $(70 \mathrm{eV})$, see Fig. $3 ;{ }^{1} \mathrm{H}$ NMR $\left(80 \mathrm{MHz}, \mathrm{CDCl}_{3}\right), \delta(\mathrm{ppm})$ $0.74\left(t,{ }^{3} \mathrm{~J}=7.8 \mathrm{~Hz}, 3 \mathrm{H} ; \mathrm{CH}_{2} \mathrm{CH}_{3}\right), 1.27\left(\mathrm{~s}, 3 \mathrm{H} ; \mathrm{CH}_{3}\right)$, $1.87\left(q,{ }^{3} \mathrm{~J}=7.5 \mathrm{~Hz}, 2 \mathrm{H}, \mathrm{CH}_{2} \mathrm{CH}_{3}\right), 7.93$ (centred $\mathrm{AA}^{\prime} \mathrm{BB}^{\prime}$ spin system, $4 \mathrm{H}$; $\mathrm{H}^{\mathrm{ar}}$ ). 6: m.p. $13-15^{\circ} \mathrm{C}$ (lit. $^{8 \mathrm{c}}$ m.p. $\left.15^{\circ} \mathrm{C}\right)$; MS $(70 \mathrm{eV})$, see Fig. $3 ;{ }^{1} \mathrm{H}$ NMR $(80 \mathrm{MHz}$, $\left.\mathrm{CDCl}_{3}\right), \delta(\mathrm{ppm}) 0.70\left(\mathrm{t},{ }^{3} \mathrm{~J}=7.8 \mathrm{~Hz}, 6 \mathrm{H} ; \mathrm{CH}_{3}\right), 1.85(\mathrm{q}$, ${ }^{3} J=7.7 \mathrm{~Hz}, 4 \mathrm{H}, \mathrm{CH}_{2}$ ), 7.93 (centred $\mathrm{AA}^{\prime} \mathrm{BB}^{\prime}$ spin system, $4 \mathrm{H} ; \mathrm{H}^{\mathrm{ar}}$ ).

1,4-Naphthoquinone (7) was used as purchased (Merck). 1-Methyl-1,4-naphthoquinol (8), m.p. 102$103^{\circ} \mathrm{C}$ (lit. ${ }^{29}$ m.p. $103-104^{\circ} \mathrm{C}$ ) was prepared from 7 and methyllithium as described in the literature. ${ }^{29} \mathrm{MS}(70$ $\mathrm{eV}), m / z 174\left(11, \mathrm{M}^{+\cdot}\right), 159,\left(100,\left[\mathrm{M}-\mathrm{CH}_{3}\right]^{+}\right), 146$ (0.25, not corrected), 145 (5), 131 (32), 129 (2), 128 (6), 127 (4), 105 (15), 103 (18), 102 (7), 91 (4), 77 (28). ${ }^{1} \mathrm{H}$ NMR (300 MHz, $\left.\mathrm{CDCl}_{3}\right), \delta(\mathrm{ppm}) 1.65\left(\mathrm{~s}, 3 \mathrm{H} ; \mathrm{CH}_{3}\right)$, $2.28(\mathrm{br}, \mathrm{s}, 1 \mathrm{H} ; \mathrm{OH}), 6.31$ and 7.03 (AB spin system, ${ }^{3} J=10.2 \mathrm{~Hz}, 2 \mathrm{H} ; 2-\mathrm{H}$ and $3-\mathrm{H}$, respectively), 7.44, $7.64,7.79$, and 8.07 (ABCD spin system, ${ }^{3} J \approx 7.7 \mathrm{~Hz}$, $\left.{ }^{4} J \approx 1.0 \mathrm{~Hz}, 4 \mathrm{H} ; \mathrm{H}^{\mathrm{ar}}\right)$.

2,2-Bis( $\beta$-phenylethyl)-1,3-indandione (9) was synthesized ${ }^{30}$ by twofold alkylation of 1,3-indandione with 1-iodo-2-phenylethane by using the $\mathrm{KF} /$ Celite method. ${ }^{11 \mathrm{~d}, 26}$ The reaction proceeds very slowly (stirring for 4 days at $70^{\circ} \mathrm{C}$ ) giving a mixture of 9 and its $C, O$-alkylated isomer, from which 9 is obtained by repeated recrystallization from light petroleum in $18 \%$ yield, m.p. $101-102{ }^{\circ} \mathrm{C} .{ }^{1} \mathrm{H}$ NMR $\left(80 \mathrm{MHz}, \mathrm{CDCl}_{3}\right), \delta$ (ppm) 2.25 (two equivalent $\mathrm{AA}^{\prime} \mathrm{BB}^{\prime}$ spin systems, $8 \mathrm{H}$; $\mathrm{CH}_{2} \mathrm{CH}_{2}$ ), 6.9-7.4 (m, $10 \mathrm{H} ; \mathrm{H}^{\mathrm{ph}}$ ), 7.90 (centred $\mathrm{AA}^{\prime} \mathrm{BB}^{\prime}$ spin system, $4 \mathrm{H}, \mathrm{H}^{\text {benzo }}$ ).

Spiro[indan-1,3-dione-2,5'-norborn- $2^{\prime}$-ene] (10), the Diels-Alder adduct of the elusive 2-methylene-1,3indandione and cyclopentadiene, was prepared by oxidation of 2-methyl-2-(phenylselenyl)-1,3-indandione ${ }^{26.31}$ with $\mathrm{H}_{2} \mathrm{O}_{2}$ in the presence of an excess of cyclopentadiene, according to a procedure developed by Bloch and Orvane. ${ }^{31}$ The compound was characterized as follows: m.p. $79^{\circ} \mathrm{C}$ (from $n$-hexane- $\mathrm{CH}_{2} \mathrm{Cl}_{2}$ (20:1), lit. $^{31}$ m.p. $\left.79^{\circ} \mathrm{C}\right)$; MS (70 eV, $m / z 224\left(26, \mathrm{M}^{+\circ}\right), 223$ (2), 181 (2), 178 (2), 159 (39), 152 (3), 115 (2), 105 (5), 104 (8), $103(3), 102(7), 91(4), 77(8), 76(16), 66\left(100, \mathrm{C}_{5} \mathrm{H}_{6}^{+*}\right), 65$ (9), 51 (6), 50 (9), 39 (11), 27 (3); ${ }^{1} \mathrm{H}$ NMR $(300 \mathrm{MHz}$, $\mathrm{CDCl}_{3}$ ), $\delta$ (ppm) 1.36 (br d) and 2.26 (d with fine splitting, AB spin system, ${ }^{2} J=-8.6 \mathrm{~Hz},{ }^{4} J \approx 1.4 \mathrm{~Hz}, 2 \mathrm{H}$; $\mathrm{CH}_{2}$ ), 1.50 (dd) and 2.15 (dd, AB spin system, ${ }^{2} J=-11.6 \mathrm{~Hz},{ }^{4} \mathrm{~J}=2.8 \mathrm{~Hz}$ and ${ }^{4} \mathrm{~J}=3.6 \mathrm{~Hz}$, respectively, $2 \mathrm{H} ; \mathrm{CH}_{2}$ ), 3.00 (br s, $1 \mathrm{H} ; 4^{\prime}-\mathrm{H}$ ), 3.16 (very br s, $1 \mathrm{H}$; bridgehead-CH, $\left.1^{\prime}-\mathrm{H}\right), 6.00\left(\mathrm{dd},{ }^{3} J=5.5 \mathrm{~Hz}\right.$ and $\left.{ }^{3} J=3.0 \mathrm{~Hz}, 1 \mathrm{H} ; \mathrm{CH}=\mathrm{CH}\right), 6.55\left(\mathrm{dd},{ }^{3} J=5.5 \mathrm{~Hz}\right.$ and $\left.{ }^{3} J=3.1 \mathrm{~Hz}, 1 \mathrm{H} ; \mathrm{CH}=\mathrm{CH}\right), 7.82\left(\mathrm{~m}, 2 \mathrm{H}, \mathrm{H}^{\mathrm{ar}}\right), 7.93(\mathrm{~m}$, $\left.1 \mathrm{H}, \mathrm{H}^{\mathrm{ar}}\right), 7.99\left(\mathrm{~m}, 1 \mathrm{H}, \mathrm{H}^{\mathrm{ar}}\right)$.

\section{Acknowledgements}

The author expresses his gratitude to Dr Robert Bloch, Université de Paris-Sud à Orsay, France, for kindly providing the procedure for the synthesis of $\mathbf{1 0}$ and for helpful discussions. He also thanks Dr Ahmad Mehdizadeh and Dr Michael Penk for early contributions to this work.

\section{REFERENCES}

1. G. Bouchoux, Mass Spectrom. Rev. 7, 1, 203 (1988).

2. Ketones and aldehydes: (a) D. J. McAdoo, C. E. Hudson and D. N. Witiak, Org. Mass Spectrom. 14, 350 (1979); (b) D. J. McAdoo and C. E. Hudson, Org. Mass Spectrom. 18, 466 (1983): (c) G. Bouchoux, Y. Hoppilliard, R. Flammang, A Maquestiau and P. Meyrant, Org. Mass Spectrom. 18, 340 (1983): (d) D. J. McAdoo, C. E. Hudson, F. W. McLafferty and T. E. Parks, Org. Mass Spectrom. 19, 353 (1984); (e) C. E. Hudson and D. J. McAdoo, Org. Mass Spectrom. 20, 402 (1985); (f) L. L. Griffin, K. Holden, C. E. Hudson and D. J. McAdoo, Org. Mass Spectrom. 21, 175 (1986); (g) M. Masur, A. Sprafke and H.-F. Grützmacher, Org. Mass Spectrom. 22, 307 (1987): (h) J. C. Traeger, C. E. Hudson and D. J. McAdoo, Int. J. Mass Spectrom. Ion Processes 82, 101 (1988).

3. Carboxylic acids: (a) D. J. McAdoo, D. N. Witiak, F. W. McLafferty and J. D. Dill, J. Am. Chem. Soc. 100, 6639 (1978); (b) D. J. McAdoo and C. E. Hudson, J. Am. Chem. Soc. 103, 7710 (1981); (c) G. Frenking, J. Schmidt and H. Schwarz, Z. Naturforsch., Teil B 37, 355 (1982); (d) J. J. Zwinselman, N. M. M. Nibbering, C. E. Hudson and D. J. McAdoo, Int. J. Mass Spectrom. Ion Processes 47, 129 (1983); (e) T. Weiske and H. Schwarz, Chem. Ber. 116, 323 (1983); (f) H. Audier and G. Sozzi, Org. Mass Spectrom. 19. 150 (1984): (g) D. J. McAdoo, C. E. Hudson, J. J. Zwinselman and N. M. M. Nibbering, J. Chem. Soc., Perkin Trans. 2 1703 (1985); (h) H. Audier, A. Milliet and G. Sozzi, Bull. Soc. Chim. Fr. 833 (1985); (i) T. Weiske, H. Halim and $H$ Schwarz, Chem. Ber. 118, 495 (1985); (j) H. Audier and G. Sozzi, Nouv. J. Chim. 10,579, (1986); (k) T. Weiske and H. Schwarz, Tetrahedron 42, 6245 (1986); (l) B. L. M. van Baar,
J. K. Terlouw, S. Akkök, K. W. Zummack and H. Schwarz, Int. J. Mass Spectrom. Ion Processes 81, 217 (1987); (m) D. J. McAdoo, C. E. Hudson, M. Skyiepal, E. Broido and L. L. Griffin, J.Am. Chem. Soc. 109, 7648 (1987).

4. Carboxylic esters: (a) A. Weisz and A. Mandelbaum, J. Chem. Soc., Chem. Commun. 521 (1978); (b) C. Wesdemiotis and H. Schwarz, Angew. Chem., Int. Ed. Engl. 17, 678 (1978); (c) P. H. Hemberger, J. C. Kleingeld, K. Levsen, N. Mainzer, A Mandelbaum, N. M. M. Nibbering, H. Schwarz, R. Weber, A. Weisz and C. Wesdemiotis, J. Am. Chem. Soc. 102, 3736 (1981); (d) E. Göksu, T. Weiske, H. Halim and H. Schwarz, J. Am. Chem. Soc. 106, 1167 (1984)

5. F. W. Mclafferty and F. Turecek, Interpretation of Mass Spectra, 4th edn., University Science Books, Mill Valley, CA (1993).

6. D. G. I. Kingston, J. T. Bursey and M. M. Bursey, Chem. Rev. 74, 215 (1974)

7. (a) R. Bar-Shai, A. Bortinger and A. Mandelbaum, Isr. J. Chem. 20, 137 (1980); (b) H. Schwarz, Top. Curr. Chem. 97. 1 (1981); (c) H. Schwarz, Nachr. Chem. Techn. Lab. 28, 158 (1980); (d) H. Schwarz, Org. Mass Spectrom. 15, 491 (1980).

8. (a) A. Schönberg and M. Mamluk, Chem. Ber. 106, 849 (1973); (b) W. R. Dolbier, Jr, K. Matsui, L. McCullagh and K. E. Anapolle, J. Org. Chem. 44, 2842 (1979): (c) A. Aebi, E. Gyurech-Vago, E. Hofstetter and P. Waser, Pharm. Acta Helv. 38, 407 (1963); (d) W. ten Hoeve and H. Wynberg, J. Org. Chem. 44, 1508 (1979); (e) Yu. Yu. Popelis, V. A. Pestunovich, I. Ya. Shternberga and Ya. F. Freimanis, $\mathrm{Zh}$. Org. Chem. 8, $1860(1972)$; (f) B. Vigante, J. Ozols and G. Duburs, Latv. PSR Zinat. Akad. Vest., Kim. Ser. 707 (1980). 
9. (a) C. F. Bernasconi and P. Paschalis, J. Am. Chem. Soc. 108 2969 (1986); (b) R. Schomäcker, K. Stickdorn and W. Knoche, J. Chem. Soc., Faraday Trans. 87, 847 (1991); (c) R. B. Kampare, Z. P. Laizane, É. É. Liepin'sh and O. Ya. Neiland, Zh. Org. Khim. 12, 1792 (1976); J. Org. Chem USSR 12, 1757 (1976); (d) M. V. Petrova, E. Liepins, J. Pauliņš and E. Gudriniece, Magn. Reson. Chem. 30, 216 (1992).

10. (a) M. L. de Winter and W. Th. Nauta, Eur. J. Med. Chem. Chim. Ther. 12, 125 (1977), and references cited therein; (b) K. Rehse and F. Brandt, Arch. Pharm. (Weinheim) 317, 54 (1984); (c) A. R. Murthy, S. D. Wyrick and I. H. Hall, J. Med. Chem. 28, 1591 (1985).

11. (a) D. Kuck, in I. Hargittai (Ed.), Quasicrystals, Networks, and Molecules of Fivefold Symmetry, Chapt. 19. VCH Publishers, New York (1990); (b) D. Kuck and H. Bögge, J. Am. Chem. Soc., 108, 8107 (1986); (c) D. Kuck, T. Lindenthal and A. Schuster, Chem. Ber. 125, 1449 (1992); (d) D. Kuck, E. Neumann and A. Schuster, Chem. Ber. 127, 151 (1994).

12. D. Kuck and A. Mehdizadeh, Org. Mass Spectrom. 27, 443 (1992).

13. S. Hammerum, Mass Spectrom. Rev. 7, 123 (1988).

14. D. J. McAdoo, Mass Spectrom. Rev. 7, 363 (1988).

15. (a) J. H. Bowie, D. H. Williams, S.-O. Lawesson and G. Schroll, J. Org. Chem. 31, 1384 (1966); (b) T. Goto, A. Tatematsu, Y. Nakajima and H. Tsujama, Tetrahedron Lett. 757 (1965).

16. M. Masur, H.-F. Grützmacher, H. Münster and H. Budzikiewicz, Org. Mass Spectrom. 22, 493 (1987).

17. (a) N. Schamp, M. Vandevalle and M. Francque, Bull. Soc. Chim. Belg. 76, 528 (1967); (b) N. Schamp and M. Vandevalle, Bull. Soc. Chim. Belg. 75, 539 (1966).

18. H.-F. Grützmacher and M. Masur, Org. Mass Spectrom. 23 , 223 (1988).

19. (a) H. Budzikiewicz, C. Djerassi and D. H. Williams, Mass Spectrometry of Organic Compounds, p. 364, Holden-Day.
San Francisco (1967); (b) J. L. Cotter and R. A. Dine-Hart, Org. Mass Spectrom. 1, 915 (1968).

20. (a) See, for example, C. F. Koelsch and E. J. Prill, J. Am Chem. Soc. 67, 1296 (1945); (b) P. Hrnčiar, A. Gáplorský, J Donovalová and L. Márton, Acta Fac. Rerum Nat. Univ. Comenianae, Chim. 38, 19 (1990).

21. R. Wolf and H.-F. Grützmacher, J. Phys. Org. Chem. 3, 301 (1990), and references cited therein.

22. R. D. Bowen, D. H. Williams and H. Schwarz, Angew. Chem., Int. Ed. Engl. 18, 451 (1979).

23. For example, see: K. Eckart, W. Zummack and H. Schwarz, Org. Mass Spectrom. 19, 642 (1984).

24. G. Thielking, U. Filges and H.-F. Grützmacher, J. Am. Soc. Mass Spectrom. 3, 417 (1992), and references cited therein.

25. (a) S. Hammerum, D. Kuck and P. J. Derrick, Tetrahedron Lett. 25, 893 (1984); (b) T. Bjørnholm, S. Hammerum and D. Kuck, J. Am. Chem. Soc. 110, 3862 (1988); (c) D. J. McAdoo and C. E. Hudson, Org. Mass Spectrom. 21, 779 (1986); (d) W. J. Bouma, R. H. Nobes and L. Radom, J. Am. Chem. Soc. 105, 1743 (1983); (e) B. F. Yates and L. Radom, Org. Mass Spectrom. 22, 430 (1987); (f) B. T. Golding and L. Radom, J. Chem. Soc., Chem. Commun. 939 (1973); (g) T. Clark and M. C. R. Symons, J. Chem. Soc., Chem. Commun. 96 (1986); (h) J. Fossey and J.-Y. Nedelec, Tetrahedron 37, 2967 (1981); (i) G. Bouchoux and Y. Hoppilliard, Int. J. Mass Spectrom. Ion Processes 55, 47 (1983/84).

26. R. Bloch and P. Orvane, Synth. Commun. 11, 913 (1981).

27. W. A. Mosher and R. W. Soeder, J. Org. Chem. 36, 1561 (1971).

28. G. E. Ullyot, H. W. Taylor, Jr, and N. Dawson, J. Am. Chem. Soc. 70, $542(1948)$.

29. D. A. Evans, J. M. Hoffman and L. K. Truesdale, J. Am. Chem. Soc. 95, 5822 (1973).

30. D. Kuck and $M$. Penk, unpublished results (1985).

31. (a) R. Bloch, personal communications $(1983,1989)$; (b) $R$. Bloch and $P$. Orvane, unpublished results. 